KEY WORDS:

Thermal Electrical Analysis

Vitrification of $\mathrm{Am} / \mathrm{Cm}$

Bushing Melter Analysis

Thermal Stress Analysis

Finite Element Analysis

Platinum-Rhodium Alloys

Power Distribution

Non-linear Elasto-plasticity

RETENTION PERIOD: LIFETIME

\title{
ELECTRICAL POWER DISTRIBUTION AND THERMAL STRESS ANALYSES FOR AN AM/CM BUSHING MELTER (U)
}

\author{
By
}

CHUNG GONG and BRUCE J. HARDY

ISSUED: NOVEMBER 1997

SRTC SAVANNAH RIVER TECHNOLOGY CENTER WESTINGHOUSE SAVANNAH RIVER COMPANY AIKEN, SC, 29808

MASTER

Prepared for the U. S. Department of Energy under Contract DE-AC09-96SR18500

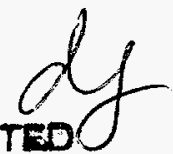




\section{DOCUMENT: $\quad$ WSRC-TR-97-0159}

\section{TITLE:}

\section{ELECTRICAL POWER DISTRIBUTION AND THERMAL STRESS ANALYSES FOR AN AM/CM BUSHING MELTER (U)}

\section{APPROVALS:}

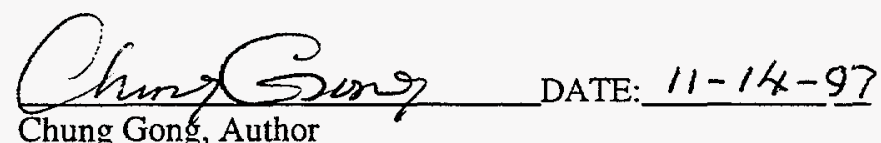

Engineering Modeling \& Simulation, Engineering Development Section

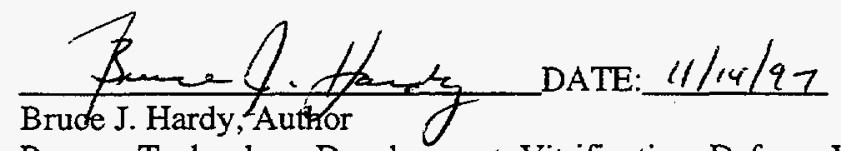

Process Technology Development, Vitrification, Defense Waste Processing Technology

PSLan DATE: $11 / 17 / 97$

Poh-Sang Lam, Technical Reviewer

Materials Applications \& Corrosion Technology, Materials Technology Section

$$
\text { Q.7. Denkins }
$$

DATE: $12-15-97$

Charles F. Jenkins, Technical Reviewer

Materials Consultations, Materials Technology Section

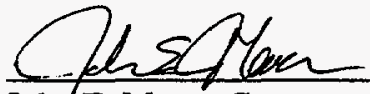
DATE: $11 / 25 / 97$

John E. Marra, Customer

Engineered Equipment \& System, Savannah River Technology Center

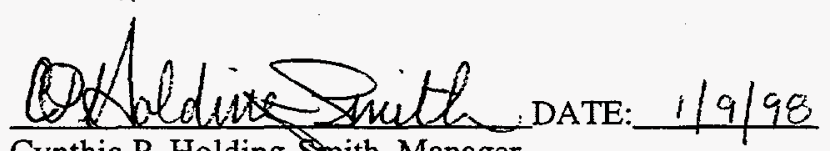

Cynthia P. Holding-Smith, Manager

Engineering Modeling \& Simulation, Engineering Development Section

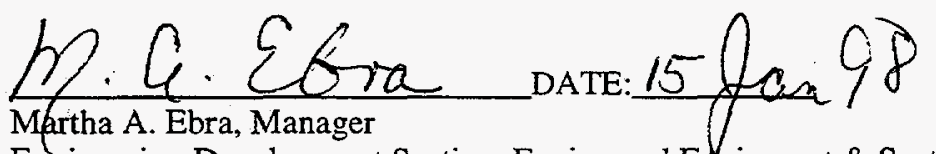

Engineering Development Section, Engineered Equipment \& System 


\section{DISCLAIMER}

This report was prepared as an account of work sponsored by an agency of the United States Government. Neither the United States Government nor any agency thereof, nor any of their employees, make any warranty, express or implied, or assumes any legal liability or responsibility for the accuracy, completeness, or usefulness of any information, apparatus, product, or process disclosed, or represents that its use would not infringe privately owned rights. Reference herein to any specific commercial product, process, or service by trade name, trademark, manufacturer, or otherwise does not necessarily constitute or imply its endorsement, recommendation, or favoring by the United States Government or any agency thereof. The views and opinions of authors expressed herein do not necessarily state or reflect those of the United States Government or any agency thereof. 


\section{DISCLAIMER}

Portions of this document may be illegible electronic image products. Images are produced from the best available original document. 


\section{CONTENTS}

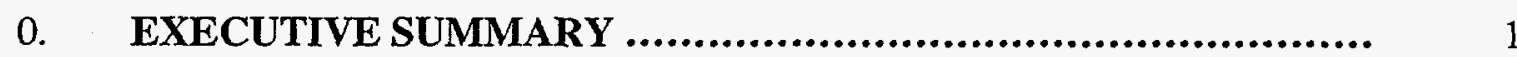

1. INTRODUCTION ..................................................... 2

2. BACKGROUND ....................................................... 3

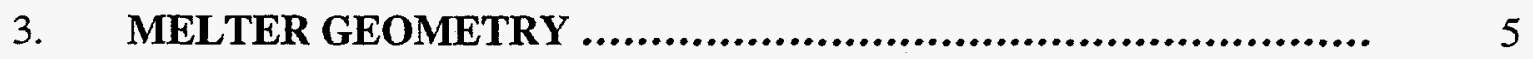

4. NUMERICAL METHODS .............................................. 5

4.1. Method of Analysis ............................................ 5

4.2. Description of the Pre- and Post-processor ............................. 6

4.3. Main Processor .......................................................... 6

4.4. Finite Element Modeling ............................................... 6

5. MATERIAL PROPERTIES ........................................... 8

5.1. Mass Density .................................................. 8

5.2. Modulus of Elasticity ............................................... 8

5.3. Yield Strength and Ultimate Tensile Strength .......................... 9

5.4. Thermal Conductivity ............................................ 13

5.5. Thermal Expansion Coefficients ................................. 14

5.6. Electrical Conductivity ........................................... 15

6. MODEL DESCRIPTION ................................................. 15

6.1. Power Distribution ............................................... 16

7. POWER DISTRIBUTION ANALYSIS ................................. 19

8. STRESS-STRAIN ANALYSIS ......................................... 22

9. CONCLUSIONS .................................................... 27

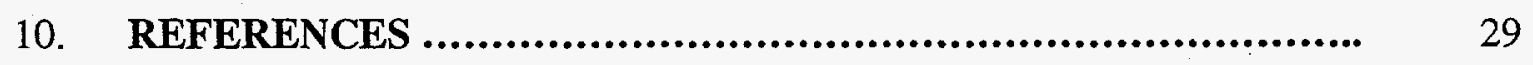

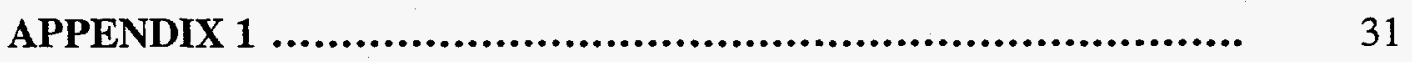

APPENDIX 2 ........................................................ 35

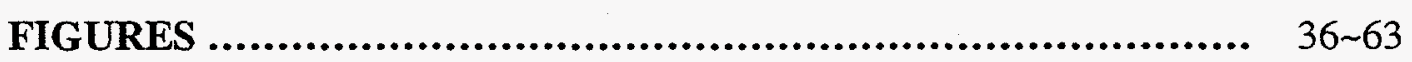




\section{LIST OF TABLES}

Table 5-1. Mass density of platinum-rhodium alloys 8

Table 5-2. The modulus of elasticity for platinum-rhodium alloys 9

Table 5-3. The yield strength and ultimate tensile strength of the hard worked $90 \%$ platinum $10 \%$ rhodium alloy

Table 5-4. The yield strength and ultimate tensile strength of the annealed $90 \%$ platinum $10 \%$ rhodium alloy

Table 5-5. The yield strength and ultimate tensile strength of the hard worked $80 \%$ platinum $20 \%$ rhodium alloy

Table 5-6 The yield strength and ultimate tensile strength of the annealed $80 \%$ platinum $20 \%$ rhodium alloy

Table 5-7. Thermal conductivity of the $60 \%$ platinum $40 \%$ rhodium alloy

Table 5-8. The Coefficients of Thermal Expansion for Platinum Rhodium Alloys 14

Table 5-9. The Electrical Conductivity of the Platinum Rhodium Alloys

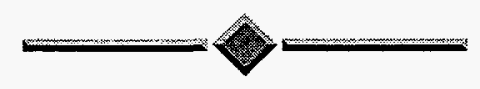

\section{LIST OF FIGURES}

Figure 1-1. Americium/Curium Vitrification Bushing Melter 2A Middle Plane Section View

Figure 1-2. Americium/Curium Vitrification Bushing Melter 2A Side Plane Section View

Figure 4-1. Americium/Curium Vitrification Bushing Melter 2A Finite Element Analysis Mesh

Figure 5-1. The Modulus of Elasticity of the Platinum-Rhodium Alloys

Figure 5-2. The Yield \& Ultimate Strength of the Platinum (90\%)-Rhodium (10\%) Alloy 
Figure 5-3. The Yield \& Ultimate Strength of the Platinum (80\%)-Rhodium (20\%) Alloy

Figure 5-4. The Thermal Conductivity of the $87 \%$ Platinum-13\% Rhodium and $60 \%$ Platinum-40\% Rhodium Alloys

Figure 5-5. The Electrical Conductivity of the $90 \%$ Platinum-10\% Rhodium and $87 \%$ Platinum-13\% Rhodium Alloys

Figure 7-1. Americium/Curium Vitrification Bushing Melter 2A Current input: $70 \%$ on Top Ears, 30\% on Bottom Ears Electrical Current Density Magnitude

Figure 7-2. Americium/Curium Vitrification Bushing Melter 2A Current input: $100 \%$ on Top Ears, $0 \%$ on Bottom Ears Electrical Current Density Magnitude

Figure 7-3. Americium/Curium Vitrification Bushing Melter 2A Current input: $70 \%$ on Top Ears, $30 \%$ on Bottom Ears Electrical Potential

Figure 7-4. Americium/Curium Vitrification Bushing Melter 2A Current input: $100 \%$ on Top Ears, 0\% on Bottom Ears Electrical Potential

Figure 7-5. Americium/Curium Vitrification Bushing Melter 2A Current input: $70 \%$ on Top Ears, $30 \%$ on Bottom Ears Electrical Energy Dissipated per unit volume

Figure 7-6. Americium/Curium Vitrification Bushing Melter 2A Current input: $100 \%$ on Top Ears, $0 \%$ on Bottom Ears Electrical Energy Dissipated per unit volume

Figure 7-7. Americium/Curium Vitrification Bushing Melter 2A Current input: $70 \%$ on Top Ears, $30 \%$ on Bottom Ears Electrical Energy Dissipated per unit volume in Large Plate

Figure 7-8. Americium/Curium Vitrification Bushing Melter 2A Current input: $100 \%$ on Top Ears, $0 \%$ on Bottom Ears Electrical Energy Dissipated per unit volume in Large Plate

Figure 7-9. Americium/Curium Vitrification Bushing Melter 2A Current input: $70 \%$ on Top Ears, $30 \%$ on Bottom Ears Electrical Current Density Vector $\mathrm{C}_{2}$ in Large Plate 
Figure 7-10. Americium/Curium Vitrification Bushing Melter 2A Current input: $100 \%$ on Top Ears, $0 \%$ on Bottom Ears Electrical Current Density Vector $\mathrm{C}_{2}$ in Large Plate

Figure 8-1. Americium/Curium Vitrification Bushing Melter 2A Finite Element Analysis Mesh for Stress Analysis

Figure 8-2. Americium/Curium Vitrification Bushing Melter 2A Displacement and von Mises Stress Distributions at the Critical Temperature $752.55^{\circ} \mathrm{C}$

Figure 8-3. Americium/Curium Vitrification Bushing Melter 2A Contour of Displacement Component 1 at $813.45^{\circ} \mathrm{C}$

Figure 8-4. Americium/Curium Vitrification Bushing Melter 2A Contour of Displacement Component 2 at $813.45^{\circ} \mathrm{C}$

Figure 8-5. Americium/Curium Vitrification Bushing Melter 2A Contour of Displacement Component 3 at $813.45^{\circ} \mathrm{C}$

Figure 8-6. Americium/Curium Vitrification Bushing Melter 2A Contour of von Mises Stress at $813.45^{\circ} \mathrm{C}$

Figure 8-7. Americium/Curium Vitrification Bushing Melter 2A Contour of Displacement Component 1 at $1450^{\circ} \mathrm{C}$

Figure 8-8. Americium/Curium Vitrification Bushing Melter 2A Contour of Displacement Component 2 at $1450^{\circ} \mathrm{C}$

Figure 8-9. Americium/Curium Vitrification Bushing Melter 2A Contour of Displacement Component 3 at $1450^{\circ} \mathrm{C}$

Figure 8-10. Americium/Curium Vitrification Bushing Melter 2A Contour of von Mises Stress at $1450^{\circ} \mathrm{C}$ 


\section{EXECUTIVE SUMMARY}

The nuclear material production at the Savannah River Site (SRS) has resulted in the generation of kilogram quantities of the isotopes $\mathrm{Am}^{243}$ and $\mathrm{Cm}^{244}$. Currently, the Am and $\mathrm{Cm}$ isotopes are stored in a tank as a nitric acid solution. The solution contains other isotopes and is intensely radioactive, which makes long term storage a problem and precludes shipment in the liquid form. The Am and $\mathrm{Cm}$ isotopes are not merely waste material, the isotopes have great commercial value but must be transferred to the Oak Ridge National Laboratory (ORNL) for processing. In order to stabilize the material for onsite storage and to transport the material from SRS to ORNL, it has been proposed that the Am and $\mathrm{Cm}$ be vitrified.

Vitrification will be effected by depositing a liquid feed stream containing the isotopes in solution, together with a stream of glass frit, onto the top of a molten glass pool in a melter. The glass is non-conducting and the melter is a platinum-rhodium alloy vessel which is heated by passing an electric current through it. Because most of the power is required to evaporate the liquid feed at the top of the glass pool, power demands differ for the upper and lower parts of the melter. In addition, the melter is batch fed so that the local power requirements vary with time. In order to design a unique split power supply, which ensures adequate local power delivery, an analysis of the melter power distribution was performed with the ABAQUS finite element code. ABAQUS was used to calculate the electric potential and current density distributions in the melter for a variety of current and potential boundary conditions. The results of the calculation were compared with test data and will be used to compute power densities for input to a computational fluid dynamics model for the melter.

Due to the nature of the vitrification process, there exist large temperature gradients in the platinum alloy vessel. Further, the local melter temperatures will vary during different phases of the vitrification process. Thermal gradients in the melter have a pronounced effect on the distribution of mechanical stress and to a lesser extent affect the power distribution through the temperature dependent resistivity. Thermal expansion of the 
melter is accommodated via movable suspension at the bottom and compressible insulation placed in strategic locations about the outside of the melter. It must be noted that the platinum-rhodium alloy composing the melter becomes very soft at operating temperatures and requires external support. Therefore, the refractory bounding the melter must provide support without being so rigid that thermal expansion cannot occur. In addition, internal stresses must be accounted for in the geometrical design of the melter. In order to estimate the thermal stress, an analysis was carried out with the finite element analysis code ABAQUS. Because the temperature distribution in the melter was unknown at the time of this analysis, the melter was assumed to be at a uniform temperature. A uniformly applied increase in the melter temperature, needed to obtain the stress distribution at operating temperatures, was treated in this analysis. Although the actual melter temperature will not be uniform, this analysis is necessary provide an basic information for the design of the melter geometry and supporting refractory. As temperature data becomes available, it will be straightforward to incorporate it into both the model for the power distribution and the thermal stress. The results of this preliminary stress analysis will be compared with available test data and the model will be upgraded as necessary to provide guidance predicting the performance of future melter designs.

\section{INTRODUCTION}

The nuclear material production at the Savannah River Site (SRS) has resulted in the generation of kilogram quantities of the isotopes $\mathrm{Am}^{243}$ and $\mathrm{Cm}^{244}$. Currently, the Am and $\mathrm{Cm}$ isotopes are stored in a tank as a nitric acid solution. The solution contains other isotopes and is intensely radioactive, which makes long term storage a problem and precludes shipment in the liquid form. The Am and $\mathrm{Cm}$ isotopes are not merely waste material, the isotopes have great commercial value but must be transferred to the Oak Ridge National Laboratory (ORNL) for processing. In order to stabilize the material for onsite storage and to transport the material from SRS to ORNL, it has been proposed that the $\mathrm{Am}$ and $\mathrm{Cm}$ be vitrified.

Vitrification will be effected by depositing a liquid feed stream containing the isotopes in solution, together with a stream of glass frit, onto the top of a molten glass pool in a melter. The glass is non-conducting and the melter is a rectangular vessel composed of 
platinum-rhodium alloy and which is resistively heated. The majority of the evaporation of water in the liquid feed occurs in the frit bed formed on the surface of the glass pool. The wetted frit bed is called a "cold cap". Because most of the power is required to evaporate the liquid, power demands differ for the upper and lower parts of the melter. In addition, the melter is batch fed so that the power requirements at the top and bottom of the melter vary with time. To vary the fraction of the total power delivered to the upper and lower parts of the melter, pairs of upper and lower electrodes were placed on the melter and connected to variable power supplies.

In order to ensure that the electrode configuration could effectively vary power between the top and bottom of the melter, and to identify regions of high power density, an analysis of the melter power distribution was performed with the ABAQUS ${ }^{\circledR}$ finite element code. ABAQUS was used to calculate the electric potential and current density distributions in the melter for a variety of current and potential boundary conditions. The results of the calculation were compared with test data and were used to compute power densities for input to a computational fluid dynamics model for the melter.

During melter heat-up, thermal expansion may cause permanent deformation. Further, the melter will operate at temperatures near $1400^{\circ} \mathrm{C}$. At these temperatures the melter is entirely in the regime of plastic deformation and the structural integrity and stability of the melter was questioned. The stress and strain in the melter during heat-up and at the operating temperature was estimated from a model based on the ABAQUS code .

This report documents the power distribution and stress calculations performed for Melters $2 \mathrm{~A}$ and $2 \mathrm{~B}$ which are to be used in the $\mathrm{Am} / \mathrm{Cm}$ vitrification program.

\section{BACKGROUND}

The design of Melters $2 \mathrm{~A}$ and $2 \mathrm{~B}$, is based on operating experience with Melter 1 .

Melter 1 was a rectangular box with a bottom which sloped toward a central drain tube. Melter 1 was approximately 11 in. tall, 10 in. wide and 2.5 in. deep. The top of the melter had a $2.5 \mathrm{in.} \mathrm{by} 10 \mathrm{in}$. rectangular opening. Each member of the electrode pairs were attached on opposite sides of the melter.

Initially, it was believed that Melter 1 could be run as a continuous process. However, operating experience dictated that it was necessary to run in batch mode. During tests 
with Melter 1, it soon became obvious that the operation of the melter must be divided into three phases; feeding, heating and a pouring. In the feeding phase, inventory is accumulated by depositing nitric acid solution and glass frit on the surface of the glass pool. The majority of the power is used to evaporate the nitric acid solution. Therefore, most of the power must be applied to the top of the melter during the feeding phase . After sufficient inventory is accumulated in the melter, the heating phase begins. In this phase the feed is stopped and the remaining liquid evaporates from the cold cap. The remaining layer of dried frit and crust is heated until it is melted into the glass pool, which is heated until an equilibrium state is reached within the melter. It is believed that the melter may be allowed to idle indefinitely at this state without adversely affecting the product or system. During the heating phase it is believed that it will be necessary to shift power toward the bottom of the melter. After equilibrium has been reached in the heating phase, the glass is ready to pour. This is the pouring phase. Glass pour is initiated by melting the solid glass in the drain tube with the drain tube heater. It is believed that the power distribution during the pouring phase will need to be uniform or shifted slightly toward the bottom of the melter.

In the Melter 1 tests it was found that radiative heat losses from the top were sufficiently high that the glass in this region was not completely melted when the plenum was in place. Because of this behavior, Melters $2 \mathrm{~A}$ and $2 \mathrm{~B}$ were designed with a partially covered top to direct thermal radiation onto the cold cap rather than allowing it to escape into the plenum. In addition, two pairs of electrodes were attached to Melters $2 \mathrm{~A}$ and $2 \mathrm{~B}$ and connected to variable power supplies. The pairs of electrodes are attached to the narrow sides of the melters at the top and bottom, see Figures 1-1 and 1-2. This electrode geometry allows the power to be varied between the top and bottom of the melter as needed for the particular phase of operation.

Excessive thermal strain was also a problem with Melter 1. Melter 1 was encased in cast refractory which did not allow for thermal expansion. Further, both the top and bottom of Melter 1 were rigidly fixed, allowing for no vertical expansion. When the melter was heated, it expanded laterally against the refractory material, which had a substantially lower coefficient of thermal expansion. In addition, the melter expanded vertically against the rigidly constrained top and bottom supports. Due to the rigid constraints, the walls of Melter 1 experienced substantial buckling and a tear was observed. It must be noted however, that the tear may have occurred during attempts to force glassy deposits into the glass pool by pushing against them with a mullite rod. 
In order to allow for vertical thermal expansion in Melters $2 \mathrm{~A}$ and $2 \mathrm{~B}$, the refractory at the bottom of the melter was supported by springs. Lateral expansion against the refractory material was accommodated by using fiberfrax (ceramic paper) as a padded spacer.

\section{MELTER GEOMETRY}

Melters $2 \mathrm{~A}$ and $2 \mathrm{~B}$ are flat, tall rectangular boxes made of platinum-rhodium alloys and were fabricated by GAFtech, Inc. of Nashville, TN. Because differences in the melter configurations are insignificant with regards to power and stress distributions, only one melter model was used for both Melters $2 \mathrm{~A}$ and $2 \mathrm{~B}$. The height of both melters is 11 inches, the width is 10 inches and the depth is 2.75 inches, see Figures $1-1$ and $1-2$.

There are two pairs of flat electrodes, referred to as "ears", on the short sides of the melter. One pair of ears primarily delivers power to the upper part of the melter while the other pair of ears primarily supplies power to the bottom. Inside the melter there are two pairs of vertical screens welded to the side walls with the longitudinal axis of the screens traversing the width of the melter. In order to relieve thermal buckling stresses, each of the screens has a cusp like bend at approximately one inch from each end. Additionally, two cross braces (in the form of an $\mathrm{X}$ ) are attached between the two top screens at a distance of three inches from ends. The middle screens are also cross braced. A flange plate is attached at the top of the melter. The melter is constructed primarily with 0.06 inches thick platinum-rhodium alloy plates. The top flange (including the drain wall) are made of 0.03 inch thick plates. The ears are 0.188 inches thick.

\section{NUMERICAL METHODS}

\subsection{Method of Analysis}

The finite element method was used to numerically model the electrical and mechanical behavior of Melters 2A and 2B. The mesh was generated with the pre-processor, MSC/PATRAN $^{\oplus}$ and the analysis was performed with the ABAQUS ${ }^{\infty}$ code. The ABAQUS POST post-processor was used to facilitate the post-processing of the results. 


\subsection{Description of the Pre- and Post-processor}

MSC/PATRAN $^{\otimes}$ [MSC/PATRAN, 1996] is a versatile geometric and graphic modeling code developed by PDA Engineering which was acquired by the MacNeal-Schwendler Corporation. The MSC/PATRAN system's ability to interface with a large array of applications is provided by the PATRAN Neutral File, the PATRAN Results File, and the Application Interface. Post-processing of the results was accomplished using ABAQUS POST.

\subsection{Main Processor}

$\mathrm{ABAQUS}^{\otimes}$ [ABAQUS, 1995], is a general purpose finite element analysis program with special emphasis on advanced linear and nonlinear structural engineering, heat transfer as well as coupled thermal-electrical applications. Hibbitt, Karlsson \& Sorensen, Inc. (HKS) developed and support this computer code. The ABAQUS version presently in use at SRS (5.5-1N) is marketed by HKS as a "Nuclear QA Grade" code that complies with the NQA-1 quality assurance standard. Details of the Quality Assurance controls for the ABAQUS code may be found in the Technical and QA Plan for ABAQUS.

\subsection{Finite Element Modeling}

Melters 2A and 2B possess symmetry with respect to two orthogonal planes. For symmetrically applied loads arising from a uniform temperature distribution, as considered in the current analysis, a quarter model cut out along the symmetry planes of the melter would be sufficient. However, in the analysis of the power distribution the electrical currents flow from the ears on one side of the melter to those on the other side. Therefore, the current density distribution is a problem of reflective symmetry about the vertical midplane which halves the short side of the melter, including the melter ears.

The model for the thermal-electric analysis will also be used for thermal-stress analysis. For the power distribution analysis, $\mathrm{ABAQUS}$ requires solid continuum elements in the model. However, the melter is constructed with thin plates, making the bending stress as well as the membrane stress are important in the structural integrity analysis. This is especially true at the corners of plate intersections. In order to show the elastic-plastic bending behavior of a plate at high temperature gradient, at least four elements are needed across the thickness of the plate comprising the melter body. Based upon experience, eight elements across the thickness of the plate result in a smoother solution, especially at the corners. But, due to limitations in available computer memory, the current model was meshed with only two elements across the thickness of the plate. For stresses below the 
yield limit of the material, the two-element approximation will provide a good approximation for the mechanical behavior of the melter. Previous calculations [Gong, 1996a, 1996b] (modeled with shell elements) indicated that if the melter were uniformly heated to $1600{ }^{\circ} \mathrm{C}$, the stresses approach twice the yield limit. Therefore, in certain regions of the melter, the resolution of the model may be insufficient to obtain accurate stress distribution. However, for the majority of the melter area the use of two elements across the thickness of the plate is acceptable. The finite element mesh of the melter is shown in Figure 4-1.

The thinnest plate in the melter is only 0.03 inches thick. In order to maintain a mathematically tolerable aspect ratio, the other dimensions of the elements were kept less than 0.12 inches (for double elements across the thickness of the plate) so that the aspect ratio was kept below 8. Initial attempts to maintain a low aspect ratio in the model resulted in an excessive increase in the number of elements. However, through several trial runs, a workable finite element model was developed The average aspect ratio of the elements in the melter was 7.35. In the top flange the aspect ratios were higher than 8 , and the maximum aspect ratio reached 32. At the normal intersections of the melter plates and screens the elements became smaller. In these dense regions the aspect ratios of the elements were on the order of 56. The total number of solid continuum elements in this model was 12,568 with 20,428 nodes (total number of variables is 40,856 ).

There were twelve circular holes on each of the top screens and two sets of double crossbars were installed to connect each pair of the top and middle screens. The cusps on both ends of each of the screens were also modeled.

The melter was meshed with 3-D solid continuum elements DC3D8E (for thermalelectrical analysis) or C3D8 (for stress analysis). These types of elements are both 8node linear brick elements with different physical variables associated at the nodes. The numerical computations for the coupled thermal-electrical analysis and thermal stress analysis are carried out with $\mathrm{ABAQUS}$. In a small transition region where the geometry precludes the use of DC3D8E or C3D8 elements, twelve DC3D6E (6-node linear triangular prism) (C3D6 for stress analysis) elements are implemented. 


\section{MATERIAL PROPERTIES}

Melters $2 \mathrm{~A}$ and $2 \mathrm{~B}$ are manufactured from platinum-rhodium alloys. Two alloys have been chosen as the primary materials for the melter: $90 \%$ platinum $10 \%$ rhodium alloy and $80 \%$ platinum $20 \%$ rhodium alloy.

There is a paucity of material data for platinum-rhodium alloys at the operating temperatures for the melter. The temperature dependent properties of platinum-rhodium alloys are not readily available from usual material handbooks. Most of the material properties of the platinum-rhodium alloys in this study were obtained from two sources; viz., a reference book [Vines, 1941] published by the International Nickel Company and from scattered pieces of information obtained from Dr. Louis Toth of Engelhard-Clal [Toth, 1996], who assisted us with our literature search. Many of the high temperature physical properties of the platinum-rhodium alloys were selectively chosen from conflicting data or extrapolated from the limited data available. All the material properties data obtained were converted into the SI system, which constitutes the system of units for this analysis.

\subsection{Mass Density}

The mass density of the platinum rhodium alloys can be found in References [Toth, 1996, ASM, 1990]. The values listed in Table 5-1 are the mass densities of the alloys at $30^{\circ} \mathrm{C}$ [ASM, 1990, p. 710, Table 8].

Table 5-1. Mass density of platinum-rhodium alloys

\begin{tabular}{|c|c|}
\hline Alloy & Density $\left(\mathrm{kg} / \mathrm{m}^{3}\right)$ \\
\hline \hline $90 \% \mathrm{Pt}-10 \% \mathrm{Rh}$ & 19,970 \\
\hline $80 \% \mathrm{Pt}-20 \% \mathrm{Rh}$ & 18,740 \\
\hline
\end{tabular}

\subsection{Modulus of Elasticity}

In this Table 5-2 the moduli of elasticity for the $90 \%$ platinum $10 \%$ rhodium alloy and the $70 \%$ platinum $30 \%$ rhodium alloy are digitized from the curves obtained by applying ultrasonic techniques [Papadakis et al., 1974]. The modulus for the 80\% platinum 20\% rhodium alloy is computed by averaging the moduli of the neighboring alloys. The digitized temperature dependent elastic moduli for the platinum-rhodium alloys are plotted in Figure 5-1. The yield limit of a metal decreases with increasing temperature. The Poisson's ratio of a metal usually increases with increasing temperature, but in the plastic state most metals are virtually incompressible, i.e., the Poisson's ratio approaches 
0.5. Based on general experience with material behavior and mathematical models for the constitutive properties [Malvern, 1969; ABAQUS, 1995], the Poisson's ratio of the platinum-rhodium alloys is chosen as 0.33 for the range of temperatures in this analysis.

Table 5-2. The modulus of elasticity for platinum-rhodium alloys

\begin{tabular}{|c||c|c|c|}
\hline \multirow{2}{|c||}{$\begin{array}{c}\text { Temperature } \\
\left({ }^{\circ} \text { C }\right)\end{array}$} & \multicolumn{3}{|c|}{ Modulus of Elasticity $(\boldsymbol{M P a})$} \\
\hline 0 & Pt90Rh10 & Pt80Rh20 & Pt70Rh30 \\
\hline 50 & 193,000 & 219,500 & 246,000 \\
\hline 100 & 191,000 & 217,250 & 243,500 \\
\hline 200 & 189,000 & 214,500 & 240,000 \\
\hline 300 & 185,000 & 209,990 & 234,980 \\
\hline 400 & 181,000 & 205,250 & 229,500 \\
\hline 500 & 176,000 & 199,500 & 223,000 \\
\hline 600 & 171,500 & 194,250 & 217,000 \\
\hline 700 & 167,500 & 188,725 & 209,950 \\
\hline 800 & 163,000 & 182,500 & 202,000 \\
\hline 900 & 157,500 & 176,750 & 196,000 \\
\hline 1000 & 152,500 & 171,250 & 190,000 \\
\hline 1100 & 147,500 & 165,750 & 184,000 \\
\hline 1200 & 142,500 & 159,250 & 176,000 \\
\hline 1300 & 137,000 & 153,000 & 169,000 \\
\hline 1400 & 129,000 & 144,000 & 159,000 \\
\hline 1500 & 120,000 & 135,000 & 150,000 \\
\hline 110,000 & 125,500 & 141,000 \\
\hline
\end{tabular}

\subsection{Yield Strength and Ultimate Tensile Strength}

The characteristic mechanical behavior of platinum-rhodium alloys at elevated temperatures has profound effects in the analysis of the $\mathrm{Am} / \mathrm{Cm}$ bushing melter. The thermal loading as well as the mechanical loading during the vitrification operation will inflict both geometrical and material nonlinearities upon the melter.

In a nonlinear analysis, the mechanical behavior of the material determines the distribution of stress and strain in the structure. Therefore, a knowledge of the relation between stress and strain over the full range of the operational temperatures is required. Large deformations of a structure alters the distribution of stiffness, will affect the load bearing capacity of the structure.

The search for temperature dependent mechanical properties of the platinum-rhodium alloys is still in progress. A bit of information was provided by Dr. Toth of Engelhard [Toth, 1996]. In the Table "Hot Tensile Strength" of the referenced document, the ultimate tensile strength and elongation of 17 platinum alloys are listed for temperatures 
range from $500{ }^{\circ} \mathrm{C}$ to $1600{ }^{\circ} \mathrm{C}$. According to Dr. Toth, these data are valid for hard worked wires 0.050 inches in diameter. The sample length was 18 inches, whereas the furnace length was 12 inches. The sample was heated for 5 minutes. It was found that the ultimate tensile strength was reduced by $75 \%$ from the last annealing. The data listed in the Table are in the British units and the ultimate tensile strength and elongation for $90 \%$ platinum $10 \%$ rhodium and $80 \%$ platinum $20 \%$ rhodium alloys were converted into SI units. In an analysis with material nonlinearity and/or geometrical nonlinearity, true stress and natural strain should be used in the constitutive equations [Malvern, 1969]. The ultimate tensile strength and elongation which were measured in engineering units were transformed into true and natural measurements for the finite element analysis.

The yield strength of a material plays an important role, particularly in the nonlinear analysis. In the elastic state, before reaching the yield limit, the mechanical behavior of the material is essentially linear. Beyond the yield limit the material enters the plastic state. In the plastic region the strength of the material varies with the increase of strain and the stress strain relation is nonlinear. The yield strength as well as the stress strain curve of the platinum alloys are not available in general. However, Dr. Toth [Toth, 1996] provided yield strength data for 7 annealed platinum alloys at room temperature. Because additional references were unavailable, it was assumed that the ratio of the yield limit to the ultimate tensile strength of an alloy remained constant as the temperature increases. At room temperature, the ultimate tensile strength of $90 \%$ platinum $10 \%$ rhodium and $80 \%$ platinum $20 \%$ rhodium alloys can be found in [Vines, 1941, Table 41 ].

Because only the yield strength and ultimate tensile strength were available, the stressstrain curve was approximated as two straight line segments. The corresponding strains can be computed from the modulus of elasticity and the elongation (the percentage of elongation that is measured at the point of rupture). The ultimate strain is about $80 \%$ of the rupture strain. Of course, the ratio of the ultimate strain to the rupture strain varies with alloys and temperatures and the ultimate strains of the annealed alloys may differ from those of hard worked alloys. In reality, as temperature increases, the discrepancy between the hard worked and the annealed alloys diminishes. Due to the lack of sufficient data to show the difference, the ultimate strains of the hard worked alloys were also applied to the annealed alloys.

As suggested by Dr. Toth, the yield strength of the platinum alloys were taken to be about $20 \% \sim 25 \%$ of their ultimate tensile strengths. The yield strength of the annealed $90 \%$ 
platinum $10 \%$ rhodium alloy $(18.3 \mathrm{ksi})$ is also within $20 \% \sim 25 \%$ of the ultimate tensile strength of the hard worked alloy. Therefore, the room temperature yield strength was applied to both hard worked and annealed $90 \%$ platinum $10 \%$ rhodium alloy. At high temperatures the mechanical behavior of both the hard worked and annealed platinum alloys approach the same plateau. The ultimate tensile strength of the annealed $90 \%$ platinum 10\% rhodium alloy was found in [Vines, 1941, Table 42]. The bi-linear stress strain relations for the $90 \%$ platinum $10 \%$ rhodium alloy were converted into SI units and are listed in Tables 5-3 and 5-4 as functions of temperature. The yield strength and ultimate tensile strength of both hard worked and annealed $90 \%$ platinum $10 \%$ rhodium alloy are plotted in Figure 5-2 with respect to temperature.

The temperature dependent ultimate tensile strength of the $80 \%$ platinum $20 \%$ rhodium alloy was directly converted from a table provided by Toth [Toth, 1996]. However, the yield strength for the annealed alloy could not be adopted for the hard worked $80 \%$ platinum $20 \%$ rhodium alloy. The room temperature ultimate tensile strength of the $80 \%$ platinum $20 \%$ rhodium alloy was quoted from [Vines, 1941, Table 41]. The yield limit of the alloy is taken as $20 \%$ of the ultimate tensile strength. The yield strength and the ultimate tensile strength of the hard worked $80 \%$ platinum $20 \%$ rhodium alloy are listed as functions of temperature in Table 5-5. The yield strength and ultimate tensile strength of both hard worked and annealed $80 \%$ platinum $20 \%$ rhodium alloy are shown in Figure 5-3.

Table 5-3. The yield strength and ultimate tensile strength of the hard worked $90 \%$ platinum $10 \%$ rhodium alloy

\begin{tabular}{|c||c||c||c|}
\hline $\begin{array}{c}\text { Temperature } \\
\left({ }^{\circ} \mathbf{C}\right)\end{array}$ & $\begin{array}{c}\text { Yield Strength } \\
(\mathbf{M P a})\end{array}$ & $\begin{array}{c}\text { Ultimate Tensile } \\
\text { Strength } \\
(\mathbf{M P a})\end{array}$ & $\begin{array}{c}\text { Natural Strain } \\
(\%)\end{array}$ \\
\hline \hline 20 & $1.261748 E+02$ & $6.267373 E+02$ & $7.968170 E-01$ \\
\hline 500 & $1.051457 E+02$ & $5.326233 E+02$ & $2.371653 E+00$ \\
\hline 600 & $9.154686 E+01$ & $4.817466 E+02$ & $5.448819 E+00$ \\
\hline 700 & $7.864898 E+01$ & $4.293461 E+02$ & $8.434115 E+00$ \\
\hline 800 & $6.505014 E+01$ & $3.679065 E+02$ & $1.133287 E+01$ \\
\hline 900 & $3.252507 E+01$ & $2.319411 E+02$ & $3.074847 E+01$ \\
\hline 1000 & $2.004778 E+01$ & $1.607109 E+02$ & $4.081282 E+01$ \\
\hline 1100 & $1.710370 E+01$ & $1.387923 E+02$ & $4.187103 E+01$ \\
\hline 1200 & $1.640273 E+01$ & $1.331041 E+02$ & $4.187103 E+01$ \\
\hline 1300 & $1.401943 E+01$ & $1.137642 E+02$ & $4.187103 E+01$ \\
\hline 1400 & $1.093515 E+01$ & $8.873608 E+01$ & $4.187103 E+01$ \\
\hline 1500 & $9.252822 E+00$ & $7.508437 E+01$ & $4.187103 E+01$ \\
\hline 1600 & $7.850879 E+00$ & $5.559967 E+01$ & $3.015850 E+01$ \\
\hline
\end{tabular}


Table 5-4. The yield strength and ultimate tensile strength of the annealed $90 \%$ platinum $10 \%$ rhodium alloy

\begin{tabular}{|c||c||c||c||}
\hline $\begin{array}{c}\text { Temperature } \\
\left({ }^{\circ} \mathrm{C}\right)\end{array}$ & $\begin{array}{c}\text { Yield Strength } \\
(\mathbf{M P a})\end{array}$ & $\begin{array}{c}\text { Ultimate Tensile } \\
\text { Strength } \\
(\mathbf{M P a})\end{array}$ & $\begin{array}{c}\text { Natural Strain } \\
(\%)\end{array}$ \\
\hline 20 & $1.261748 E+02$ & $3.342599 E+02$ & $7.968170 E-01$ \\
\hline 500 & $8.411656 E+01$ & $2.272526 E+02$ & $2.371653 E+00$ \\
\hline 700 & $6.834471 E+01$ & $1.989839 E+02$ & $8.434115 E+00$ \\
\hline 900 & $4.731557 E+01$ & $1.799543 E+02$ & $3.074847 E+01$ \\
\hline 1100 & $2.812647 E+01$ & $1.217277 E+02$ & $4.187103 E+01$ \\
\hline 1300 & $2.050341 E+01$ & $8.873608 E+01$ & $4.187103 E+01$ \\
\hline 1500 & $1.472040 E+01$ & $6.370795 E+01$ & $4.187103 E+01$ \\
\hline
\end{tabular}

Table 5-5. The yield strength and ultimate tensile strength of the hard worked $80 \%$ platinum $20 \%$ rhodium alloy

\begin{tabular}{||c||c||c||c||}
\hline $\begin{array}{c}\text { Temperature } \\
\left({ }^{\circ} \mathbf{C}\right)\end{array}$ & $\begin{array}{c}\text { Yield Strength } \\
(\mathbf{M P a})\end{array}$ & $\begin{array}{c}\text { Ultimate Tensile } \\
\text { Strength } \\
(\mathbf{M P a})\end{array}$ & $\begin{array}{c}\text { Natural Strain } \\
(\%)\end{array}$ \\
\hline 20 & $1.792648 E+02$ & $9.106652 E+02$ & $1.587335 E+00$ \\
\hline 500 & $1.294843 E+02$ & $6.629598 E+02$ & $2.371653 E+00$ \\
\hline 600 & $9.638930 E+01$ & $4.935132 E+02$ & $2.371653 E+00$ \\
\hline 700 & $1.012157 E+02$ & $5.141756 E+02$ & $1.587335 E+00$ \\
\hline 800 & $8.577131 E+01$ & $4.460108 E+02$ & $3.922071 E+00$ \\
\hline 900 & $5.833001 E+01$ & $3.103156 E+02$ & $6.203539 E+00$ \\
\hline 1000 & $3.378452 E+01$ & $2.297347 E+02$ & $3.074847 E+01$ \\
\hline 1100 & $2.385601 E+01$ & $1.612666 E+02$ & $3.015850 E+01$ \\
\hline 1200 & $2.109809 E+01$ & $1.434670 E+02$ & $3.074847 E+01$ \\
\hline 1300 & $1.751279 E+01$ & $1.113814 E+02$ & $2.405905 E+01$ \\
\hline 1400 & $1.475487 E+01$ & $9.443118 E+01$ & $2.468601 E+01$ \\
\hline 1500 & $1.130747 E+01$ & $8.277070 E+01$ & $3.811724 E+01$ \\
\hline 1600 & $9.101136 E+00$ & $6.443604 E+01$ & $3.478360 E+01$ \\
\hline
\end{tabular}

The ultimate tensile strength of annealed $80 \%$ platinum $20 \%$ rhodium alloy at room temperature can be found in [Vines, 1941, Table 41]. The yield strength is given in [Toth, 1996] . Nevertheless, the relationship between the ultimate tensile strength and yield strength as a function of temperature is still unknown. The yield strength and the ultimate tensile strength of annealed $80 \%$ platinum $20 \%$ rhodium alloy as a function of temperature are listed in Table 5-6. It should be noted that these values are applied under the assumption that the strength ratios between the annealed and the hard worked alloy do not vary with increasing temperature. 
Table 5-6 The yield strength and ultimate tensile strength of the annealed $80 \%$ platinum $20 \%$ rhodium alloy

\begin{tabular}{|c||c||c||c|}
\hline $\begin{array}{c}\text { Temperature } \\
\left({ }^{\circ} \boldsymbol{C}\right)\end{array}$ & $\begin{array}{c}\text { Yield Strength } \\
(\mathbf{M P a})\end{array}$ & $\begin{array}{c}\text { Ultimate Tensile } \\
\text { Strength } \\
(\mathbf{M P a})\end{array}$ & $\begin{array}{c}\text { Natural Strain } \\
(\%)\end{array}$ \\
\hline \hline 20 & $1.206590 E+02$ & $4.903582 E+02$ & $1.587335 E+00$ \\
\hline 500 & $8.715292 E+01$ & $3.569784 E+02$ & $2.371653 E+00$ \\
\hline 600 & $6.487742 E+01$ & $2.657379 E+02$ & $2.371653 E+00$ \\
\hline 700 & $6.812593 E+01$ & $2.768638 E+02$ & $1.587335 E+00$ \\
\hline 800 & $5.773069 E+01$ & $2.401597 E+02$ & $3.922071 E+00$ \\
\hline 900 & $3.926058 E+01$ & $1.670930 E+02$ & $6.203539 E+00$ \\
\hline 1000 & $2.273958 E+01$ & $1.237033 E+02$ & $3.074847 E+01$ \\
\hline 1100 & $1.605693 E+01$ & $8.683587 E+01$ & $3.015850 E+01$ \\
\hline 1200 & $1.420064 E+01$ & $7.725146 E+01$ & $3.074847 E+01$ \\
\hline 1300 & $1.178746 E+01$ & $5.997458 E+01$ & $2.405905 E+01$ \\
\hline 1400 & $9.931164 E+00$ & $5.084756 E+01$ & $2.468601 E+01$ \\
\hline 1500 & $7.610798 E+00$ & $4.456884 E+01$ & $3.811724 E+01$ \\
\hline 1600 & $6.125765 E+00$ & $3.469633 E+01$ & $3.478360 E+01$ \\
\hline
\end{tabular}

\subsection{Thermal Conductivity}

In view of the fact that platinum-rhodium alloys are used extensively for high temperature applications, it is somewhat surprising that the thermal properties of platinum-rhodium alloys are particularly scarce. Insofar as the authors could discern, the specific heat data for the alloys are simply not available. Only a few experimentally obtained values for thermal conductivity could be found for two different platinum rhodium alloys, namely, $87 \%$ platinum $13 \%$ rhodium and the $60 \%$ platinum- $40 \%$ rhodium. Test data for the $87 \%$ platinum-13\% rhodium alloy was fitted with least squares into a simple formula [Mølgaard, 1968]:

$$
K_{P R}=60.7-9.2\left(10^{3} / T\right)
$$

where: $K_{P R}=$ thermal conductivity of the $87 \%$ platinum- $13 \%$ rhodium alloy in $\mathrm{W} /{ }^{\circ} \mathrm{K} \mathrm{m}$

$T=$ temperature in ${ }^{\circ} \mathrm{K}$.

Test data for the $60 \%$ platinum- $40 \%$ rhodium alloy was provided by Dr. Louis Toth [Toth, 1996]. The thermal conductivity as a function of temperature is listed in Table 57. The thermal conductivity curves of the two alloys are shown in Figure 5-4. 
Table 5-7. Thermal conductivity of the $60 \%$ platinum $40 \%$ rhodium alloy

\begin{tabular}{|c|c||c|c|}
\hline Temperature & Temperature & $\begin{array}{c}\text { Thermal } \\
\text { Conductivity } \\
\text { Cal/sec/cm/ } /\end{array}$ & $\begin{array}{c}\text { Thermal } \\
\text { Conductivity } \\
\text { Watt/m } \text { K }\end{array}$ \\
\hline \hline 250 & ${ }^{\circ} \boldsymbol{C}$ & 0.105 & 43.97 \\
\hline 400 & -23.15 & 0.120 & 50.25 \\
\hline 600 & 126.85 & 0.140 & 58.63 \\
\hline 800 & 326.85 & 0.155 & 64.91 \\
\hline 1000 & 526.85 & 0.165 & 69.10 \\
\hline 1200 & 726.85 & 0.172 & 72.03 \\
\hline 1400 & 926.85 & 0.180 & 75.38 \\
\hline 1600 & 1126.85 & 0.182 & 76.21 \\
\hline 1800 & 1326.85 & 0.187 & 78.31 \\
\hline
\end{tabular}

\section{5-5. Thermal Expansion Coefficients}

Linear thermal expansion ratios (i.e., the ratio of the expanded length to the undeformed length, $\left(\mathrm{L}_{\mathrm{t}} / \mathrm{L}_{\mathrm{o}}\right)$ ) were provided by Dr. Toth [Toth, 1996, Table VIII]. The coefficients of thermal expansion were then computed from the linear thermal expansion ratios as listed in Table 5-8.

Table 5-8. The Coefficients of Thermal Expansion for Platinum Rhodium Alloys

\begin{tabular}{|c|c|c|c|c|}
\hline \multirow{3}{*}{$\begin{array}{c}\text { Temperature } \\
{ }^{\circ} \mathrm{C}\end{array}$} & \multicolumn{4}{|c|}{ Thermal Expansion Coefficient } \\
\hline & \multicolumn{2}{|c|}{ Pt $(90 \%)-R h(10 \%)$} & \multicolumn{2}{|c|}{$P t(80 \%)-R h(20 \%)$} \\
\hline & $L_{t} / L_{0-1.0}$ & Strain/K & $L_{t} / L_{0}-1.0$ & Strain/K \\
\hline$\overline{0}$ & $\overline{0}$ & $0.00000000 E+00$ & 0 & $0.00000000 E+00$ \\
\hline 100 & 0.001 & $1.00000000 E-05$ & 0.00063 & $6.30000000 E-06$ \\
\hline 200 & 0.002 & $1.00000000 E-05$ & 0.0014 & $7.00000000 E-06$ \\
\hline 300 & 0.003 & $1.00000000 E-05$ & 0.0023 & $7.666666667 E-06$ \\
\hline 400 & 0.0041 & $1.02500000 E-05$ & 0.0032 & $8.00000000 E-06$ \\
\hline 500 & 0.0051 & $1.02000000 E-05$ & 0.0043 & $8.60000000 E-06$ \\
\hline 600 & 0.0061 & $1.01666667 E-05$ & 0.0053 & $8.83333333 E-06$ \\
\hline 700 & 0.0072 & $1.02857143 E-05$ & 0.0063 & $9.00000000 E-06$ \\
\hline 800 & 0.0083 & $1.03750000 E-05$ & 0.0075 & $9.37500000 E-06$ \\
\hline 900 & 0.0094 & $1.04444444 E-05$ & 0.0087 & $9.66666667 E-06$ \\
\hline 1000 & 0.0106 & $1.06000000 E-05$ & 0.0099 & $9.90000000 E-06$ \\
\hline 1100 & 0.0117 & $1.06363636 E-05$ & 0.0112 & $1.01818182 E-05$ \\
\hline 1200 & 0.0131 & $1.09166667 E-05$ & 0.0125 & $1.04166667 E-05$ \\
\hline 1300 & 0.0144 & $1.10769231 E-05$ & 0.0138 & $1.06153846 E-05$ \\
\hline 1400 & 0.0158 & $1.12857143 E-05$ & 0.0152 & $1.08571429 E-05$ \\
\hline 1500 & 0.0176 & $1.17333333 E-05$ & 0.0167 & $1.11333333 E-05$ \\
\hline
\end{tabular}




\subsection{Electrical Conductivity}

If the temperature is not extremely low, the Wiedemann-Franz law states that the ratio of the thermal conductivity to the electrical conductivity for a metal is directly proportional to the temperature. Further, the value of the proportionality constant is independent of the particular metal [Kittel, 1966]. The electrical conductivities of the $90 \%$ platinum $10 \%$ rhodium and $87 \%$ platinum $13 \%$ rhodium alloys are derived from the resistivity listed in Table 39 of [Vines, 1941, page 89]. With both thermal conductivity and electrical conductivity computed from the experimental data, the Lorenz number defined by the Wiedemann-Franz law can be obtained. The derived temperature dependent electrical conductivites of the platinum-rhodium alloys are listed in Table 5-9.

Table 5-9. The Electrical Conductivity of the Platinum Rhodium Alloys

\begin{tabular}{|c||c|c|}
\hline \multirow{2}{*}{$\begin{array}{c}\text { Temperature } \\
{ }^{\circ} \boldsymbol{C}\end{array}$} & \multicolumn{2}{|c|}{ Electrical Conductivity (1/ohm-Meter) } \\
\hline \hline 0.0 & $\begin{array}{l}\text { 90\% Platinum } \\
\text { I0\% Rhodium }\end{array}$ & $\begin{array}{l}\text { 87\% Platinum } \\
\text { 13\% Rhodium }\end{array}$ \\
\hline 100.0 & $5.434783 E+06$ & $5.263158 E+06$ \\
\hline 200.0 & $4.661049 E+06$ & $4.552905 E+06$ \\
\hline 300.0 & $4.086303 E+06$ & $4.023821 E+06$ \\
\hline 400.0 & $3.647505 E+06$ & $3.614806 E+06$ \\
\hline 500.0 & $3.301812 E+06$ & $3.287419 E+06$ \\
\hline 600.0 & $3.022682 E+06$ & $3.017866 E+06$ \\
\hline 700.0 & $2.791362 E+06$ & $2.792126 E+06$ \\
\hline 800.0 & $2.596647 E+06$ & $2.601660 E+06$ \\
\hline 900.0 & $2.432759 E+06$ & $2.440036 E+06$ \\
\hline 1000.0 & $2.293157 E+06$ & $2.301337 E+06$ \\
\hline 1100.0 & $2.171307 E+06$ & $2.180264 E+06$ \\
\hline 1200.0 & $2.064103 E+06$ & $2.073742 E+06$ \\
\hline 1300.0 & $1.968411 E+06$ & $1.978631 E+06$ \\
\hline 1400.0 & $1.882502 E+06$ & $1.893222 E+06$ \\
\hline 1500.0 & $1.804976 E+06$ & $1.816135 E+06$ \\
\hline
\end{tabular}

The curves of the electrical conductivity of the alloys are also plotted in Figure 5-5. The figure shows that the electrical conductivity curves of the two alloys coalesce at high temperatures.

\section{MODEL DESCRIPTION}

Three major fields of physics, namely, heat transfer, electrical conduction and continuum mechanics are coupled in the processes modeled in this analysis. The distribution of the power density due to current flow in the platinum alloy vessel results in a temperature 
gradient. The temperature distribution affects the electrical and thermal resistivity of the alloy. To a lesser extent, other effects of temperature on the material properties are conspicuous in testing, for instance, the Thomson effect [Jones, 1956] shows the coupling of thermal and electrical currents on power distribution. Other factors, such as the effect of deformation on electric potential gradients (the Bardeen and Shockley effect), etc. also impact the properties of the medium. As noted previously in this report, the mechanical properties of the alloy are dependent upon temperature. The differential thermal expansion produced by the temperature gradients determines the stress distribution, and so on. Therefore, it was essential to make assumptions about property dependence and temperature distributions to make this analysis tractable.

First, it was assumed that the constitutive properties of the platinum alloy depend only on temperature. Second, and more importantly, as a first approximation it was assumed that the temperature of the melter vessel was uniform. By the second assumption, stress distributions arise solely from the boundary constraints and internal geometry of the melter.

\subsection{Power Distribution}

The power distribution in the melter was calculated by employing the direct current electrical model in the ABAQUS code. This model exploits the fact that Fourier's law for heat conduction is mathematically identical to the microscopic form of Ohm's law.

The ABAQUS calculations give the current density vector and the electric potential in the melter shell. The power density is obtained from the simple relation

$$
q^{\prime \prime \prime}=-\frac{1}{\rho} \mathbf{j} \cdot \nabla \phi
$$

where: $q^{\prime \prime}=$ power density

$\mathbf{j}=$ current density vector

$\rho=$ electrical resistivity

$\phi=$ electric potential.

The power supply applies a 60 cycle alternating current across upper and lower pairs of ears (electrodes) located on the narrow sides of the melter. The fraction of the total current delivered to the top and bottom ears is based on the power demands during the particular phase of melter operation. The glass and refractory material are non- 
conductive and so, current flows only in the platinum alloy melter shell. Current flow across the potential gradients in the melter results in the dissipation of electrical energy. Because the ABAQUS code can only provide calculations for direct current, the numerical model of the power distribution described a DC power source operating at the RMS power of the actual AC power supply. At the frequency of the actual AC power supply, it is believed that the DC model will provide an accurate estimate of the actual $\mathrm{AC}$ power distribution.

Because the glass and refractory material are non-conducting, the current and/or electric potential are used to specify boundary conditions at the ears. For the calculations discussed in this report, the electric current was used as the boundary condition on the melter ears. The configuration of the external circuitry requires that the same amount of current entering an upper ear exits from the upper ear on the opposite side of the melter and current entering a lower ear exits from the lower ear on the opposite side of the melter. The total power was split between the upper and lower parts of the melter by changing the fraction of the total current applied to the upper and lower ears. The total current applied to the model for Melters 2A and 2B were based on the RMS power demands and the potential drop for Melter 1 , which were $13.5 \mathrm{~kW}$ and 3.5 volts, respectively. From the Melter 1 data

$$
i=\frac{P}{v}=\frac{13.5 \times 10^{3} \mathrm{~W}}{3.5 \text { volts }}=3857.1429 \mathrm{amps}
$$

where: $\quad \mathrm{i}=$ current in amps

$\mathrm{P}=$ power in Watts

$\mathrm{v}=$ potential drop in volts.

Because, as discussed previously, plane symmetry was invoked for the power distribution model, the total applied current is halved. The total current is thus 1928.5715 amps.

It must be noted that the geometry of Melter 1 differed significantly from that of Melters 2A and 2B. Further, Melter 1 only had one pair of ears. The difference in geometry and in the points of entry changes the current paths through the melter and therefore, the effective resistance. Hence, for the same current applied across Melter 1 and across Melters 2A and 2B, different potential drops and correspondingly different total powers will be obtained. For a given current split between the upper and lower ears of Melters 
$2 \mathrm{~A}$ and $2 \mathrm{~B}$, the local power density varies proportionally with the total power used in the calculation in this document. That is, for an arbitrary total power and one of the power splits used in this analysis, the corrected local power densities are obtained by multiplying the power densities obtained in this analysis by the ratio of the new total power to the total power used in this analysis. Scaling to obtain the correct local power density will be particularly important for thermal models which require adjustment of the total power.

The material used for this model was the $90 \%$ platinum $10 \%$ rhodium alloy, the temperature dependent electrical properties of which were discussed in a previous section. Because the melter is filled with molten glass at approximately $1450^{\circ} \mathrm{C}$, the melter was assumed to be uniformly at this temperature for the calculations in this report. The power distributions obtained from the ABAQUS calculations will be used in detailed heat transfer calculations. The resulting melter temperature profile will be applied to the resistivity and the distribution of the power density will be recalculated. If significant differences are noted, the heat transfer calculations will be repeated and the melter temperature distribution used to determine new electrical resistivities. This process will be repeated until the difference in the power distribution is deemed sufficiently small.

In order to examine the ability to distribute power between the top and bottom of the melter, four current and potential boundary conditions were applied to the ears [Hardy, 1996].

Case 1. $70 \%$ of the total current enters the top left ear and exits the top right ear. $30 \%$ of the total current enters the bottom left ear and exits the bottom right ear. The clamp on the upper ear is to be located at the bottom of the ear.

Case 2.: $100 \%$ of the current enters the top left ear and exits the top right ear. The current entering the bottom left ear and exiting the bottom right ear is set to zero. The clamp on the upper ear is to be located at the bottom of the ear.

Case 3. 70\% of the current enters the top left ear and the potential applied to the top right ear is set to zero. $30 \%$ of the total current enters the bottom left ear and the potential applied to bottom right ear is set to zero. The clamp on the upper ear is to be located at the bottom of the ear. 
Case 4. $100 \%$ of the current enters the top left ear and the potential applied to the top right ear is set to zero. The current entering the bottom left ear is set to zero and the potential applied to bottom right ear is set to zero. The clamp on the upper ear is to be located at the bottom of the ear.

The current in the lower ears is controlled by a saturable core reactor (SCR). Hypothetically, if the reactor were to lose power, the only resistance to current flow in the external circuit for the lower ears would be the loop impedance, which is much lower than that across the melter. Therefore, if all the current were sent to the upper ears and the SCR in the lower circuit lost power, the path of least resistance would be from the top ear to the adjacent bottom ear, through the lower current loop, into the bottom ear on the opposite side of the melter and out through the top ear of the melter. The transmission of the total current through a narrow region of the melter body between the top and bottom ears might result in excessive heating and burn through. This accident scenario necessitated the consideration of another case.

Case 5. $100 \%$ of the total current enters the top left ear and exit the top right ear. The bottom ears are connected by loop having low impedance.

\section{POWER DISTRIBUTION ANALYSIS}

The thermal-electrical analysis option was first implemented in version $5.5-1 \mathrm{~N}$ of ABAQUS, released at the end of 1995. Because the option for electrical analysis with ABAQUS (which was developed mainly for structural and thermal analysis) is new, there is not a great deal of experience with these calculations. Therefore, the predictions of the code were investigated by testing the sensitivity of the predictions to the input parameters and by determining whether the results were physically reasonable.

Cases 1 and 3, and Cases 2 and 4 are similar and would intuitively be expected to produce power and current distributions which are nearly identical. However, the calculations predicted a slight discrepancy between the current and power distributions in the vicinity of the top ears for corresponding cases. One reason for the difference was attributed to the fact that the line of symmetry for the potential lies along a vertical line along the centerline of the melter. Based on the current paths, the potential difference across the upper and lower ears need not be the same. Hence, the potential at the upper and lower 
ears may differ. A second reason for the discrepancy lies in the application of the boundary conditions for the electrical model. In Cases 3 and 4, a boundary condition of zero potential was prescribed over entire outer edge of the upper and lower right ears. In Cases 1 and 2, a current boundary condition was applied only along the lower portion of the ears and so, the resulting potential distribution may not be uniform along the ear edges. Because the regions over which the boundary conditions were applied were not the same, the calculations for cases 1 and 3 as well as for cases 2 and 4 yield different current and power distributions.

The results of Cases 1-4 were documented and saved in the Cray Archive. Cases 1 and 2 most accurately reflect the actual boundary conditions applied by the external circuitry of the $\mathrm{Am} / \mathrm{Cm}$ melter. Hence, the contour plots of the current, potential and power distributions for Cases 1 and 2 are included in this report.

The current density and potential distributions for Cases 1 and 2 are shown in Figures 7-1 through 7-4 and the power distribution is shown in Figures 7-5 through 7-8. In both Cases 1 and 2, the magnitude of current density increases in the vicinity of the ears of through which the current enters and exits. The magnitude of the current density is significantly greater where the screens and the narrow side walls are joined. The maximum and minimum values of the magnitudes of the current density for Case 1 and Case 2 are an order of magnitude apart. On the average, the magnitude of the current density is about $4.0 \mathrm{E}+06$ amps per square meter in the melter. Further, the contour plots show that the electrical potential (Figure 7-3 and 7-4) and the current density vector (Figures 7-9 and 7-10) are symmetrical about the vertical midplane normal to the back of the melter. The equipotential lines for the 70-30\% current split (Figure 7-3) are almost parallel to the vertical edges of the melter. It indicates that in this case, the potential does not vary significantly along the vertical axis of the melter. The shape of the electric potential distribution for the 70-30\% current split forces the power distribution in the melter to be nearly uniform in the vertical direction.

Differences exist in the power density distribution in the neighborhood of the ears for Cases 1 and 2 (see Figures 7-5 and 7-6). The power density distribution is seen in better 
resolution in Figures 7-7 and 7-8. The energy dissipated in Case 1 (with $70 \%$ of current on the top ears and $30 \%$ on the bottom ears) is slightly lower than that in Case 2 (with $100 \%$ of current on the top ears and no current on the bottom ears). The distribution of the dissipated energy in Case 1 (Figure 7-7) is essentially uniform and the average value is about $7.0 \mathrm{E}+06 \mathrm{~J} / \mathrm{m}^{3}$. In Case 2 the energy dissipated in the vicinities of the top power ears is about $1.85 \mathrm{E}+07 \mathrm{~J} / \mathrm{m}^{3}$, an order of magnitude higher than that in the bottom third of the plate. On the back plate of the melter, between the top ears, the average energy dissipated is approximately $8.8 \mathrm{E}+06 \mathrm{~J} / \mathrm{m}^{3}$. Over the bottom third of the back plate the mean value of the dissipated energy is only $3.0 \mathrm{E}+06 \mathrm{~J} / \mathrm{m}^{3}$.

From the plots of the current density vector in Figures $7-9$ and $7-10$, it can be seen that the current enters through the left ear, fans out across the back of the melter, then contracts to flow out the right ear. These figures clearly show the effect of the current split between the upper and lower ears on the distribution of the current density vector. In the case of a 70-30\% current split, the major component (across the width of the melter; the 2 axis in the model) of the current density vector spreads evenly over the large plate. Whereas, in the case with all the input current concentrated on the top left ear, the major component of the current density vector flows mostly over the top two third of the large plate. Nevertheless, except along the left and right edges of the back plate, the current density differs by less than a factor of 2 between the top and bottom sectors of the back plate.

The analysis demonstrated that by changing the distribution of applied current between the top and bottom power ears, the power density distribution could be shifted from uniform to one skewed toward the top of the melter. It should be remarked that thermal effects on the power density distribution were not addressed in this model. However, the purpose of the model was to determine if a change in the current split could deliver more power to the top of the melter, so that the rate of liquid evaporation and frit heating could be increased during the feed phase. The ability to shift the power distribution by changing the current split between the upper and lower ears was clearly demonstrated by the model. The thermal-electric analysis in this report therefore served as a parametric study which simulated power control for the vitrification process. The effects of the 
temperature distribution will be incorporated after a full thermal model has been developed.

The results obtained in Case 5, confirm the conjecture that under SCR failure, the current input into the top left ear will pass in to the lower left ear and across the low resistance loop, which connects the bottom power ears, into the right bottom ear then up to the top right ear and out of the melter. The contours of the current density indicate that the path of the electric current is from the left top ear to the left bottom ear through the lower current loop into the bottom ear on the right side of the melter and out through the right top ear of the melter. The transmission of all the current through a narrow region of the melter between the top and bottom ears has the potential for producing excessively high temperatures.

Each pair of screens is joined with a pair of cross braces (in the form of an $\mathrm{X}$ ). In the original design, a horizontal bar was also attached to the top and bottom of the cross bracing. The original design was used for the thermal-electric analysis, while the design without the horizontal bars was used for the thermal-stress analysis. In the thermalelectric analysis, it was found that the effect of the horizontal bars on the power distribution was negligible [see APPENDIX 2].

The input and output files are saved in the Cray Data Archive. The files are in the directory /archive/y6749/noscreen3.

\section{STRESS-STRAIN ANALYSIS}

Because of the exigency of this project and the lack of complete material data, a series of preliminary models of the melter were constructed. Although the assumption of a uniform temperature distribution was a reasonable first approximation for the power distribution model, the approximation may not be conservative for the stress-strain model. The reason for this difference is that temperature variations will result in nonuniform thermal expansion, which may result in significant stress concentrations in the melter. However, because an accurate thermal model was not completed at the time of 
this report, the stress analyses assumed a uniform temperature distribution in the entire melter.

In a series of preliminary stress-strain analyses, the melter was modeled with shell elements which are preferred for thin members. However, for the thermal-electric analysis used to obtain the power distribution, $\mathrm{ABAQUS}{ }^{\circledR}$ required 3-D solid continuum elements. Therefore, for the sake of consistency, the stress analysis also utilized the 3-D solid continuum elements in the model.

In preliminary studies, the stress-strain analysis of Melters $2 \mathrm{~A}$ and $2 \mathrm{~B}$ assumed that the platinum-rhodium alloy was at a uniform temperature of $1600^{\circ} \mathrm{C}$. The molten glass was modeled as a Newtonian fluid which applied hydrostatic pressure to the walls of the melter. Preliminary studies indicated that the effect of the glass pressure was negligible. Hence, in the ensuing analyses the weight of the glass was not included.

In the thermal stress analysis, the main purpose was to determine the mechanical stresses and strains applied to the melter during the vitrification process. The melter and supporting refractory consists of many components which structurally interact. Each of the components contributes to the distribution of the thermal stress in the melter. However, the inclusion of all components into the finite element model would result in a prohibitive increase the number of elements. Further, the temperature dependent thermal mechanical properties were not available for some of the insulation components. Therefore, it was necessary to make approximations which preserved the most significant characteristics of the thermal-stress behavior for the melter.

As the temperature in the melter increases and the melter expands, the physical constraints applied by the surrounding materials are not highly sensitive to moderate variations in the mechanical properties of the constraining materials. Therefore, mechanically equivalent constraints, which simulated the effect of melter expansion into the support and refractory materials, were deemed adequate for the analysis. In actual construction a layer of ceramic paper (3000 AL-4), 0.125 inches $(0.003175$ meter) thick, was inserted between the vertical surfaces of the melter and the surrounding Kaowool ${ }^{\circledR}$ $15 \mathrm{c}$ refractory boards, manufactured by Thermal Ceramics, Inc. The bottom of the melter, was insulated with KAST-O-LITE $30^{\circledR}$ castable refractory, manufactured by A. P. Green Industries, Inc. To increase its thermal resistance, the castable refractory was mixed with hollow alumina spheres. The cast refractory was supported below by 
four springs, each guided by a steel rod which allowed thermal expansion in the vertical direction. The spring constant of each of the springs is $1,453.5457 \mathrm{~N} / \mathrm{m}$.

The finite element model uses rigid surfaces to represent the refractory material. In the analysis, it is assumed that the ceramic paper compresses by $0.001 \mathrm{~m}$ without resistance, then becomes incompressible. To simulate this effect a $0.001 \mathrm{~m}$ gap was allowed between the vertical walls of the melter and the Kaowool ${ }^{\circledR}$ refractory boards. The bottom surface of the melter is in direct contact with the cast refractory, which is far more rigid than the melter at high temperature. However, the springs supporting the bottom refractory allow expansion in the vertical direction. Therefore, the constraint applied by the bottom refractory was modeled by providing numerical springs (through a rigid surface at the bottom) that have the same physical spring constant.

Again, the temperature profile in the melter was assumed to be uniform and it is recognized that thermal gradients will have a significant effect on the distribution of thermal stress. Performing an analysis for a uniform temperature will permit a preliminary evaluation of the melter stresses for the current refractory and melter geometry. Further, the model is sufficiently general that, once the estimated temperature distribution has been obtained, the uniform temperature distribution can be replaced.

The stresses in the melter at operating temperature are built up during the heating and expansion of the melter. In order to obtain the correct stress distribution at the operating temperature, the model simulates gradual heating of the melter from the ambient temperature of $20^{\circ} \mathrm{C}$ to $1450^{\circ} \mathrm{C}$. When the final temperature is reached, the stress-strain distribution is that which would be expected from uniformly increasing the melter temperature. During the gradual temperature increase the whole melter expands uniformly without distortion until the temperature reaches $752.55^{\circ} \mathrm{C}$ (see Figure $8-2$ ). At this temperature, the two narrow side walls have expanded across the initial gap and have contacted the ceramic paper. Because the paper, which is bounded by the Kaowool ${ }^{\circledR}$ boards, is assumed incompressible the narrow sides of the melter are horizontally compressed against rigid boundary surfaces. Simultaneously, the bottom of the melter moves vertically downward by $0.00222 \mathrm{~m}$ by compressing the support springs. The back plate is under in-plane compression, remains nearly flat and moves normally outward by $0.0003 \mathrm{~m}$. The screens deflect slightly. In this state, the entire melter shell is at the verge of structural instability. The configuration and boundary conditions of the melter are structurally complex. The potential buckling mode is not well defined, because each of 
the structural members in the melter system may have its specific mode shape. At each increment of temperature the individual buckling mode changes and consequently, through mutual interaction the aggregate (global) mode of instability also varies. Mathematically, this condition implies that the tangential stiffness of the system approaches a singularity. At this state, in this multi-degree-of-freedom system, if a multiple eigenvalue bifurcation point is perturbed, secondary bifurcations occur in the neighborhood [Marsden and Hughes, 1983]. The complicated stress, strain and stiffness relations in the governing differential equations approach a bifurcation point. In a global sense, it appears that as the temperature reaches a critical value, the whole system approaches a bifurcation point. Therefore, as the temperature approaches $752.55^{\circ} \mathrm{C}$ convergence was achieved by reducing the incremental temperature to very small values. Due to the presence of the bifurcation point, $752.55^{\circ} \mathrm{C}$ is the critical temperature for a quasi-linear stability analysis of this structural system. However, in this nonlinear elastic-plastic analysis, the calculation continued past the bifurcation points which occurred at a number of spatial locations as the temperature exceeded $752.55^{\circ} \mathrm{C}$. As the temperature increased beyond $752.55{ }^{\circ} \mathrm{C}$ the flat plates in the melter began to bend. Because the stiffness of the system did not completely vanish at the bifurcation points the critical temperature may be considered as a pseudo-critical temperature.

The melter is fabricated with thin plates and shells and at high temperatures the melter walls are structurally weak and structural as well as numerical instability occurs. Limited by the size and precision of the computer, the thin plates and shells were modeled with only two brick elements across its thickness. In the linear elastic state, the stresses calculated by $\mathrm{ABAQUS}{ }^{\circledR}$ for a thin plate with two elements across the thickness exceed the analytically calculated stresses by one-quarter. However, in a perfectly plastic state the difference between the stresses calculated by $A B A Q U S^{\circledR}$ for a thin plate with two elements across its thickness and analytically calculated stresses will diminish. As a consequence, the thermal-mechanical stresses calculated in this analysis are slightly conservative. Therefore, the true critical temperature should be higher than $752.55{ }^{\circ} \mathrm{C}$ and in the plastic region, the computed deformation and stresses are fairly reliable.

In the temperature range from $758{ }^{\circ} \mathrm{C}$ to $912{ }^{\circ} \mathrm{C}$, the back plate continues to bend normally outward with the maximum displacement occurring at the center of the plate. The location of the maximum outward displacement gradually expands and moves upward as temperature increases. The narrow side walls are braced with the thick ears and the power screens shows little or no deformation in the beginning. The part of the 
wall where there are no lateral supports begins to be displaced inward as the temperature approaches $764^{\circ} \mathrm{C}$. The hood starts to twist and the bottom of the melter warps slightly when temperature approaches to $777^{\circ} \mathrm{C}$. A portion of the back plate touches the rigid boundary surface as the temperature approaches $912{ }^{\circ} \mathrm{C}$. The deformation of the melter in this temperature range is shown by displacement contours at $813.45^{\circ} \mathrm{C}$, which are shown in Figures 8-3 through 8-5. The von Mises equivalent stress [APPENDIX 1] in the melter at $813.45^{\circ} \mathrm{C}$ is displayed in Figure 8-6. For temperatures above $912{ }^{\circ} \mathrm{C}$, the back plate reverses its curvature and bends concavely inward. That is that the center region of the side plate bends toward the interior of the melter by $0.0033827 \mathrm{~m}$, as shown in Figure 8-7. Meanwhile, the center section of the screens move toward the back plate by $0.0027675 \mathrm{~m}$ at $1450{ }^{\circ} \mathrm{C}$ from their undeformed clearance of $0.017526 \mathrm{~m}$. The crossbar braces between the pairs of screens prevent them from touching each other. However, with the interference of the glass and a non-uniform temperature distribution, the screens may be severely distorted. The contours of other two displacement components $\left(\mathrm{u}_{2}\right.$ and $\mathrm{u}_{3}$ ) at $1450{ }^{\circ} \mathrm{C}$ are shown in Figures 8-8 and 8-9.

At the plate junctions (between the back plate, side walls and bottom plate; and between the top flange, hood and the dome) the magnitude of the strain reaches $2.0 \%$. At the junctions, the melter was predicted to be in plastic yield at temperatures above $752.55^{\circ} \mathrm{C}$. However, padding the melter with ceramic paper there gives sufficient space for thermal expansion and the maximum von Mises equivalent stress [APPENDIX 1] are far below the ultimate tensile strength assumed for the alloy at corresponding temperatures (see Figure 8-10). Elsewhere, the distribution of strain is fairly uniform and the magnitude of the maximum strain remains in the neighborhood of $1.0 \%$ for all temperatures during heat up. The accumulated thermal strains incurred during the heating of the melter are well below the ultimate strains at the corresponding temperatures.

The finite element analysis of the quarter model of the melter (see Figure 8-1) was carried out on the CRAY J916 at SRS. The calculation took 65.83 CPU hours (76.19 hours wall clock time) for 130 calculation increments. The temperature increment in the calculation was reduced to less than $0.071{ }^{\circ} \mathrm{C}$ during the convergence iteration after the melter temperature reached $752.55{ }^{\circ} \mathrm{C}$. A total of 950 iterations were performed in the calculation.

The input and output files of the thermal stress analysis are saved in the Cray Data Archive. The files are in the director: /archive/y6749/m2astress. 


\section{CONCLUSIONS}

The ABAQUS thermal-electric analysis was carried out for five sets of boundary conditions. Four of these represented possible current and potential boundary conditions which could be applied to the upper and lower pairs of ears (electrodes) for the melter. Of these four cases, two, which required that the current entering an upper or lower ear exited the corresponding upper or lower ear on the opposite side of the melter, accurately represented the external circuitry for the melter. The 60 cycle alternating current power supply was approximated as a direct current source in the ABAQUS ${ }^{\circledR}$ model. At 60 cycles per second, the frequency is sufficiently low that a direct current model appears to be a reasonable approximation. Electrical resistivities for the platinum alloy at $1450^{\circ} \mathrm{C}$ were used in all calculations. From the current density vectors and electric potentials calculated by $\mathrm{ABAQUS}^{\circledR}$, it was found that changing the current splits from $100 \% / 0 \%$ to $70 \% / 30 \%$ (top/bottom), resulted in a significant shift of the power distribution from the top to the bottom of the melter. Hence, the model demonstrated that it was possible to use upper and lower pairs of electrodes to change the power distribution as needed during different phases of the vitrification process. The power densities calculated from the thermal-electric model were used as input to a computational fluid dynamics model for the melter. The model was also used to calculate the effective resistances between the ears of the melter, which were required to design the unique split power supply.

The fifth boundary condition, which connected the two bottom ears with a low impedance loop, was used to determine if SCR failure for the lower power supply could short circuit the melter from the upper to the lower ears on each side. The model indicated that shorting was possible and that high power densities in the melter could result.

In the actual melter, the temperature profile will not be uniform. Non-uniform temperatures will affect the thermal-electric analysis through the temperature dependent electrical resistivity for the platinum alloy. In order to determine the dependence of power densities on temperature gradients in the melter, the temperature distribution from the computational fluid dynamics calculation will be applied to the thermal-electric model. If the effect of temperature gradients is found to be significant, the updated power densities will be supplied to the computational fluid dynamics model and the melter temperature profile will be re-calculated. If the new temperature profile differs significantly from that calculated with the original power density distribution, the new 
temperatures will be substituted into the thermal-electric model. This iterative process will be continued until convergence occurs.

The melter stress analysis was a first approximation of the stresses introduced during the vitrification process. Because precise mechanical properties were unavailable for the platinum alloy at elevated temperatures, approximations were made. The model also incorporated approximations for the external constraints applied by the refractory material surrounding the melter. By using a model developed with the ABAQUS ${ }^{(B}$ software, the uniform heating of the melter to a temperature of $1450^{\circ} \mathrm{C}$ was simulated. During the heat-up, thermal expansion against the external refractory and internal structural members provided an estimate for the stress-strain distribution for the melter at the operating temperature. The model indicated that the use of ceramic paper as spacers between the vertical refractory boards and the spring suspension used to support the bottom of the melter, allows for thermal expansion without extreme deformation. Further, it was found that at the intersections of plates the melter was in plastic yield at temperatures above $752.55^{\circ} \mathrm{C}$. From the uniform temperature calculations, it was found that greatest strains (approximately $2.0 \%$ ) occurred at the junctions of the walls and the junction of the walls with the bottom of the melter. The remaining components of the melter experienced strains of less than $1.0 \%$. All strains in the melter were found to be well below the ultimate strain at the corresponding temperatures.

Because there will be large temperature gradients during the feeding of the melter, actual stresses and strains will be greater than those calculated in this report. The effect of the large temperature gradients will be estimated by first assuming a temperature profile in the melter during the feeding process and later by applying the temperatures calculated from the computational fluid dynamics model. The current stress analysis model is sufficiently general that a temperature profile can be directly applied. The temperature dependency of all mechanical properties is incorporated into the model so that they will be automatically calculated for an input temperature profile.

This document was prepared in conjunction with work done under Contract No. DE-AC09-96SR18500 with the U.S. Department of Energy. By acceptance of this document, the publisher and/or recipient acknowledges the U.S. Government's rights to retain a non-exclusive, royalty-free license in and to any copyright covering this document, along with the right to reproduce and to authorize others to reproduce all or part of the copyright material. 


\section{REFERENCES}

ABAQUS ${ }^{\circledR}$ (version 5.5-1N), 1995, ABAQUS Theory Manual, Hibbitt, Karlsson \& Sorensen, Inc. 1080 Main Street, Pawtucket, RI 02860-4847.

APGreen, 1992, KAST-O-LITE ${ }^{\circledR}$ 30, A. P. Green, Industries, Inc., Mexico, Missouri, 65265, Tel., 314-473-3626, Fax, 314-473-3330.

ASM, 1990, Metals Handbook, tenth edition, volume 2, ASM International Handbook Committee.

Fung, Y. C., 1965, "Foundations of Solid Mechanics", Prentice-Hall, Inc., Englewood Cliffs, New Jersey.

Gong, C., 1996a, "Thermal Stress Analysis for Am/Cm Remelt Bushing No. 1", Memorandum to David R. Muhlbaier, SRT-EMS-96-0025, March 28, 1996.

Gong, C., 1996b, "Thermal Stress Analysis for Am/Cm Remelt Bushing No. 2", Memorandum to Mark R. Duignan, SRT-EMS-96-0034, April 18, 1996.

Hardy, B. J., 1996, "Power Distributions for Melter 2A", Memorandum to C. Gong, SRTAMC-96-0039, August 26, 1996.

Hill, R., 1950, "The Mathematical Theory of Plasticity," chapter $\Pi$, section 2, pp. 14-23, Oxford at the Clarendon Press.

Jones, H., 1956, "Theory of Electrical and Thermal Conductivity in Metals", in Handbuch der Physik (Encyclopedia of Physics), vol. XIX, Electrical Conductivity I, Edited by S. Flügge, Springer-Verlag, Berlin.

Kittel, C., 1966, Introduction to Solid State Physics, Third edition, John Wiley \& Sons, Inc., New York.

Malvern, L. E., 1969, Introduction to the Mechanics of a Continuous Medium, PrenticeHall, Inc., Englewood Cliffs, New Jersey.

Marsden, J. E., Hughes, T. J. R., 1983, Mathematical Foundations of Elasticity, PrenticeHall, Inc., Englewood Cliffs, New Jersey.

Mølgaard, J., and Smeltzer, W. W., 1968, "The thermal conductivity of $87 \%$ platinum 13\% rhodium alloy", Short Communications, Journal of the Less-Common Metals, 16 (1968) pp. 275 278.

MSC/PATRAN ${ }^{\circledR}$ (version 5.0), 1996, Installation \& Operations Manual, The MacNealSchwendler Corporation, 815 Colorado Boulevard, Los Angeles, CA 90041.

Özisik, M. N., 1985, HEAT TRANSFER, A Basic Approach, McGraw-Hill Book Company, New York. 
Papadakis, E. P., Fowler, K. A., Lynnworth, L. C., Robertson, A., and Zysk, E. D., 1974, "Ultrasonic measurements of Young's modulus and extensional wave attenuation in refractory metal wires at elevated temperatures with application to ultrasonic thermometry", Journal of Applied Physics, Vol. 45, No. 6, June 1974. pp. 2409 2420.

Toth, Louis, 1996, Private communications ENGELHARD-CLAL, LP, 700 Blair Road, Carteret, New Jersey 07008, Telephone (908) 205-5870, Fax phone (908) 205-7476.

Vines R. F., 1941, The Platinum Metals and Their Alloys, Edited by E. M. Wise, The International Nickel Company, Inc., New York. 


\section{APPENDIX 1}

\section{A.1 Incremental plasticity theory}

Incremental plasticity theory is based on a few fundamental postulates. A basic assumption of elastic-plastic models is that the deformation can be separated into an elastic part and a plastic part. In its most general form this statement is written as:

$$
\mathbf{F}=\mathbf{F}^{e l} \cdot \mathbf{F}^{p l}
$$

where $\mathbf{F}$ is the total deformation gradient, $\mathbf{F}^{\text {et }}$ is the fully recoverable part of the deformation at the point under consideration, and $\mathbf{F}^{p l}$ is defined by $\mathbf{F}^{p l}=\left[\mathbf{F}^{e l}\right]^{-1} \cdot \mathbf{F}$. The rigid body rotation at the point may be included in the definition of either $\mathbf{F}^{e l}$ or $\mathbf{F}^{p l}$ or may be considered separately before or after either part of the decomposition. Conventionally an additive strain rate decomposition:

$$
d \varepsilon=d \varepsilon^{e l}+d \varepsilon^{p l}
$$

has been used. Here $d \varepsilon$ is the total mechanical strain rate; $d \varepsilon^{e l}$ is the elastic strain rate; and $d \varepsilon^{p l}$ is the plastic strain rate.

In ABAQUS, when the elastic strains are infinitesimal, the rate of deformation definition:

$$
d \varepsilon=s y m m\left[\frac{\partial v}{\partial x}\right] d t
$$

is applied to the total strain rate in the algorithms developed for all of the plasticity models. Practically the elastic strains in platinum-rhodium alloys are considerably small as compared with the inelastic deformations in the melter system. Thus, the use of the additive strain rate decomposition for the models in this analysis is an acceptable approximation. 
The elastic part of the response is assumed to be derivable from an elastic strain energy density potential, so that the stress is defined by:

$$
\sigma=\partial U / \partial \varepsilon^{e l}
$$

where $U$ is the strain energy density potential. Based on the assumption that in the absence of plastic straining, the variation of elastic strain is the same as the variation in the rate of deformation, conjugacy arguments define the stress measure $\sigma$ as the true (Cauchy) stress. For the elastic plastic model of von Mises which will be applied to the platinum-rhodium alloys, the elasticity is linear, so that the strain energy density potential has a simple form. The yield functions $f_{i}$ define the limit to the region of pure elastic response, i.e.,

$$
f_{i}\left(\sigma, \theta, H_{\alpha}\right)<0
$$

for pure elastic response. Here $\theta$ is the temperature, and $H_{\alpha}$ are a set of hardening parameters.

When the material is flowing inelastically the inelastic part of the deformation is defined by a flow rule, which can be written as

$$
d \varepsilon^{p l}=\Sigma_{i} d \lambda_{i}\left[\frac{\partial g_{i}}{\partial \sigma}\right]
$$

where $g_{i}\left(\sigma, \theta, H_{i, \alpha}\right)$ is the flow potential for the $i$ th system, and $d \lambda_{i}$ is a scalar measuring the amount of the plastic flow rate on the $i$ th system.

\section{A.2 von Mises Equivalent Stress}


The deformation of a solid body can be decomposed into two patterns, a dilatational mode (in which the solid changes volume), and an equivoluminal mode (in which the solid maintains constant volume, but distorts its shape). The corresponding stress fields are the hydrostatic and the deviatoric stresses.

For an isotropic material the criterion of yielding (i.e., in the state of plastic deformation), is a function of the stress state in the material element. In other words, the function is a constitutive law which must be independent of coordinate orientation. Then the yield criterion can be put in the form:

$$
q=f\left(J_{2}, J_{2}, J_{3}\right)
$$

where $J_{1}, J_{2}$, and $J_{3}$ are the first three invariants of stress tensor $\sigma_{\mathrm{ij}}$.

Experimental work [Hill, 1950] has shown that for most metals (including steel and platinum alloys) the hydrostatic stress has no influence on yielding. In 1913, von Mises suggested that yielding occurred when $J_{2}^{\prime}$ (the second invariant of deviatoric stresses) reached a critical value, and that the yielding function may not involve $J_{3}^{\prime}$, the third invariant of deviatoric stresses. $J_{3}^{\prime}$ is not considered because its value changes from positive to negative for a triaxial state of stress that changes from tensile to compressive, and the isotropic material yielding does not depend on whether the stresses are tensile or compressive [Malvern, 1969]. In terms of deviatoric stresses, von Mises' yielding criterion can be written as:

$$
\begin{aligned}
& q=f\left(J_{2}^{\prime}\right), \\
& J_{2}^{\prime}=\frac{1}{2} s_{i j} s_{i j},
\end{aligned}
$$

where $s_{\mathrm{ij}}$ is the deviatoric stress tensor [Fung, 1965], 


$$
s_{i j}=\sigma_{i j}-\frac{1}{3} \sigma_{k k} \delta_{i j} .
$$

Then in terms of Cauchy stresses, $\sigma_{i j}$

$$
J_{2}^{\prime}=\frac{1}{2}\left(\sigma_{i j} \sigma_{i j}-\frac{1}{3} \sigma_{i j} \sigma_{k k}\right) .
$$

In terms of principal stresses,

$$
J_{2}^{\prime}=\frac{1}{6}\left[\left(\sigma_{1}-\sigma_{2}\right)^{2}+\left(\sigma_{2}-\sigma_{3}\right)^{2}+\left(\sigma_{3}-\sigma_{1}\right)^{2}\right] .
$$

If $\sigma_{y}$ is the yield strength of the material, then the von Mises yielding criterion can be expressed as:

$$
q=\sigma_{y^{\prime}}
$$

where $\mathrm{q}$ is the von Mises equivalent stress, in terms of principal stresses:

$$
q=\sqrt{3 J_{2}^{\prime}}=\left\{\frac{1}{2}\left[\left(\sigma_{1}-\sigma_{2}\right)^{2}+\left(\sigma_{2}-\sigma_{3}\right)^{2}+\left(\sigma_{3}-\sigma_{1}\right)^{2}\right]\right\}^{\frac{1}{2}}
$$

For materials exhibiting strain hardening properties, the equivalent stress or the true stress is a generalized yield criterion for any loading increase that causes additional plastic deformation according to the incremental theory of plasticity.

For a material with appreciable different responses in tension and compression, such as soil, the third invariant of the deviatoric stresses, $\mathrm{J}_{3}$, may be included in the material model.

$$
J_{3}^{\prime}=\frac{1}{3} s_{i j} s_{j k} s_{k i} .
$$




\section{APPENDIX 2}

The cross bar braces between each pair of the top screens and middle screens have virtually no effects in the thermal electrical analysis. Because the major component of the electrical current is in the direction parallel to the length of the screens, i.e., the flow of current is perpendicular to the plane of the cross bar braces. In the thermal stress analysis, however, the strength of the braces will influence the stress strain distribution in the melter. The original design of the braces includes top and bottom horizontal bars in addition to the cross bars (in $\mathrm{X}$ shape). The final design will drop the horizontal bars. In order to show that the severance of the horizontal bars has little or no affects on the thermal electrical analysis, the problem of Case 1 is rerun without the horizontal bracing bars. The comparison of the maximum and minimum values is shown in the table:

\begin{tabular}{|c|c|c|c|c|c|}
\hline \multirow[b]{2}{*}{$\begin{array}{l}\text { Electrical } \\
\text { Quantity }\end{array}$} & \multirow[b]{2}{*}{$\begin{array}{l}\text { Member of } \\
\text { the Model }\end{array}$} & \multicolumn{2}{|c|}{ Maximum Value } & \multicolumn{2}{|c|}{ Minimum Value } \\
\hline & & $\begin{array}{c}\text { with } \\
\text { Horizontal } \\
\text { Bars }\end{array}$ & $\begin{array}{c}\text { without } \\
\text { Horizontal } \\
\text { Bars }\end{array}$ & $\begin{array}{c}\text { with } \\
\text { Horizontal } \\
\text { Bars }\end{array}$ & $\begin{array}{c}\text { without } \\
\text { Horizontal } \\
\text { Bars }\end{array}$ \\
\hline $\begin{array}{l}\text { Energy } \\
\text { Density } \\
\end{array}$ & Whole & $9.9356 E+07$ & $9.9356 E+07$ & $3.4213 E-09$ & $1.3730 E+01$ \\
\hline $\begin{array}{l}\text { Energy } \\
\text { Density }\end{array}$ & $\begin{array}{l}\text { Front } \\
\text { Plate }\end{array}$ & $1.2517 E+07$ & $1.2517 E+07$ & $1.0862 E+06$ & $1.0862 E+06$ \\
\hline $\begin{array}{l}\text { Energy } \\
\text { Density } \\
\end{array}$ & $\begin{array}{c}\text { Top } \\
\text { Flange } \\
\end{array}$ & $3.9437 E+06$ & $3.9437 E+06$ & $2.3427 E+03$ & $2.3427 E+03$ \\
\hline $\begin{array}{l}\text { Energy } \\
\text { Density }\end{array}$ & Top Screen & $3.2710 E+07$ & $3.2710 E+07$ & $3.4214 E-09$ & $7.0403 E+01$ \\
\hline $\begin{array}{l}\text { Energy } \\
\text { Density }\end{array}$ & $\begin{array}{l}\text { Middle } \\
\text { Screen }\end{array}$ & $4.7352 E+07$ & $4.7352 E+07$ & $1.6403 E-01$ & $1.3730 E+O I$ \\
\hline Potential & Whole & $5.5086 E-01$ & $5.5091 E-01$ & $-5.6915 E-01$ & $-5.6911 E-01$ \\
\hline $\begin{array}{c}\text { Magnitude of } \\
\text { the Potential } \\
\text { gradient }\end{array}$ & Whole & $7.4926 E+00$ & $7.4926 E+00$ & $3.1233 E-08$ & $2.0344 E-03$ \\
\hline $\begin{array}{c}\text { Magnitude of } \\
\text { the Current } \\
\text { Density }\end{array}$ & $\begin{array}{c}\text { Whole } \\
\text { - }\end{array}$ & $1.3260 E+07$ & $1.3260 E+07$ & $5.5277 E-02$ & $3.6006 E+03$ \\
\hline $\begin{array}{c}\text { Current } \\
\text { Density in } \\
\text { the Direction } \\
\text { between } \\
\text { Opposite } \\
\text { Ears }\end{array}$ & Whole & $1.5216 E+06$ & $1.5216 E+06$ & $-1.2405 E+07$ & $-1.2405 E+07$ \\
\hline
\end{tabular}




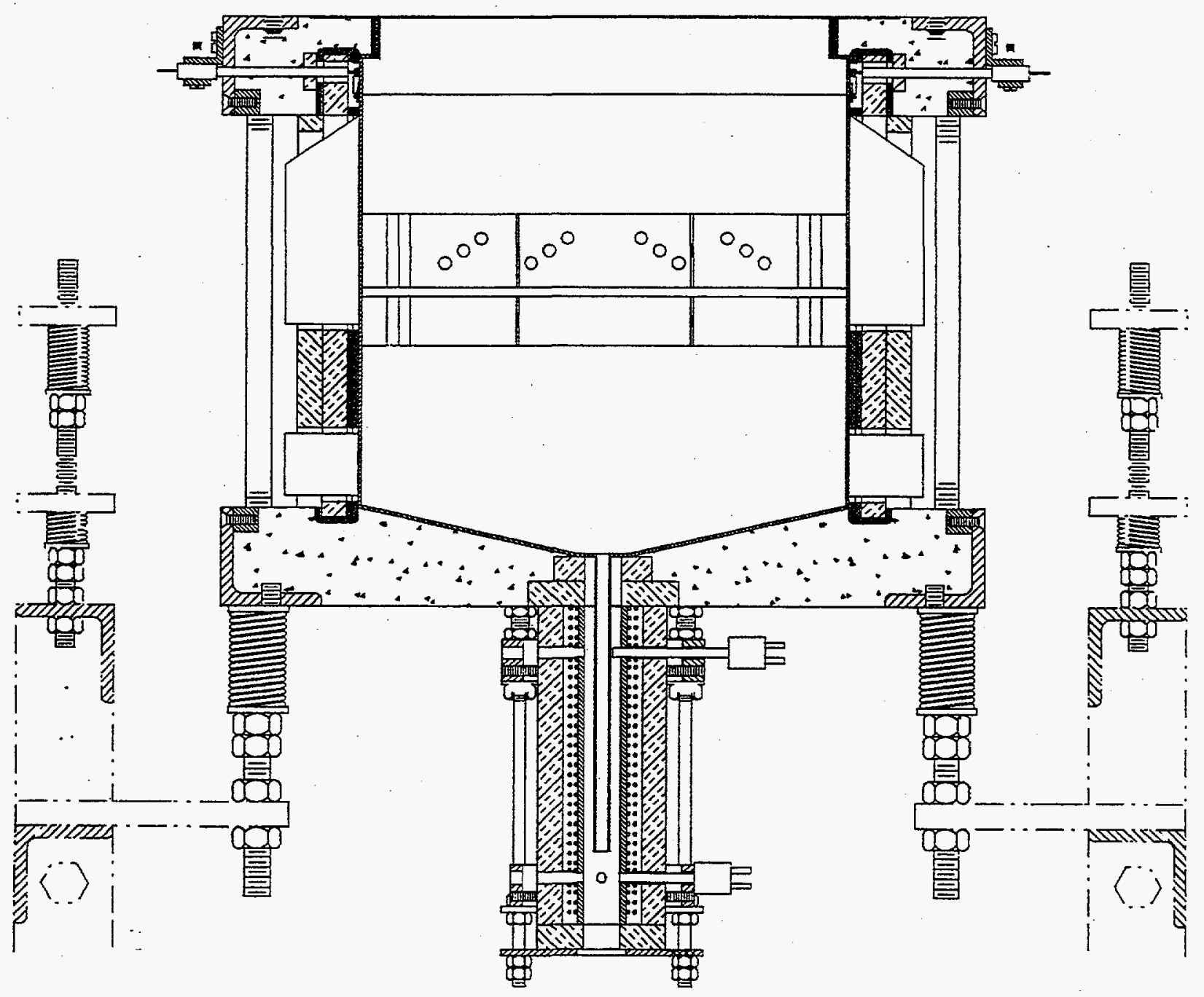

Figure 1-1. Americium/Curium Vitrification Bushing Melter 2A Middle Plane Section View. 


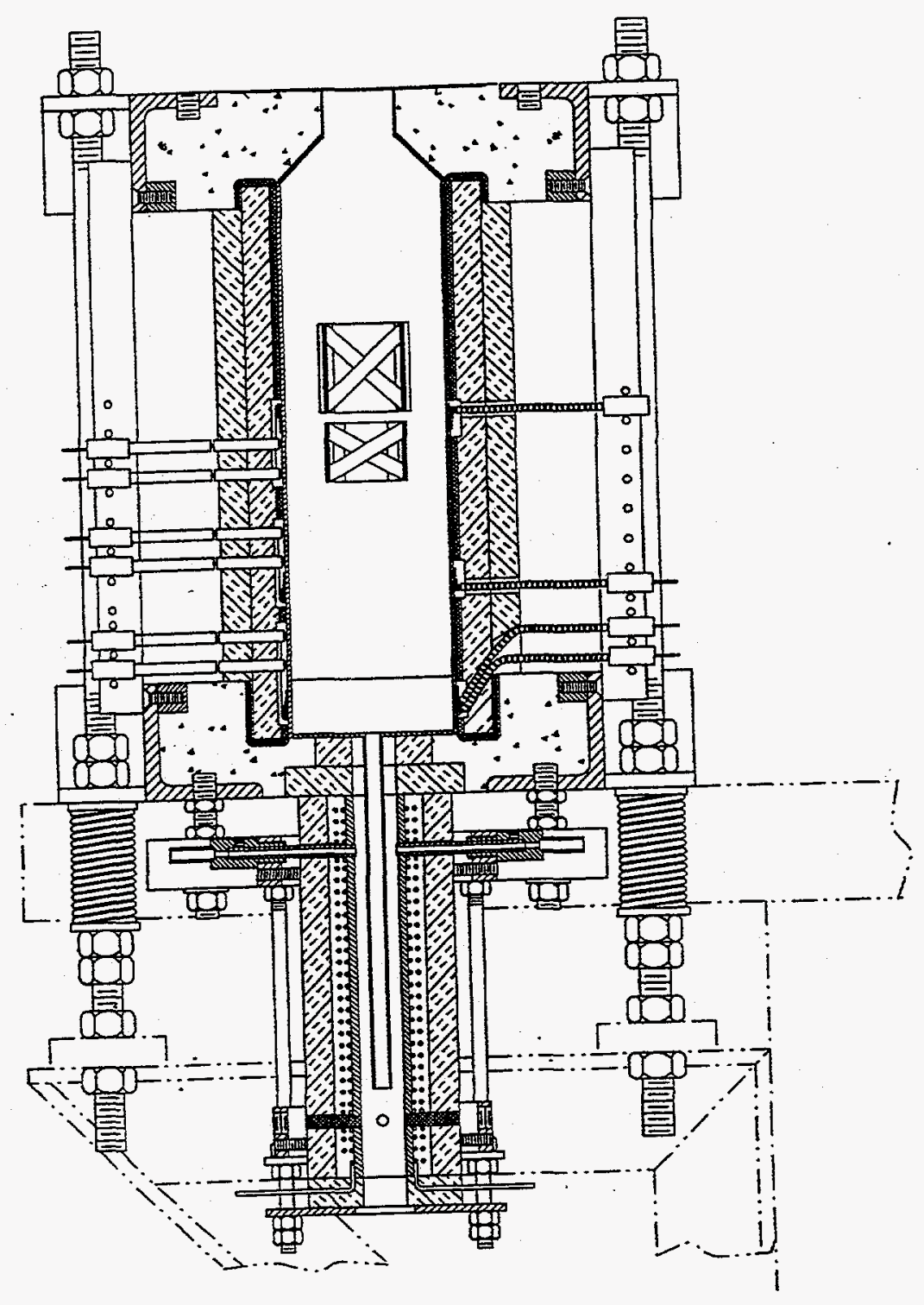

Figure 1-2. Americium/Curium Vitrification Bushing Melter 2A Side Plane Section View 

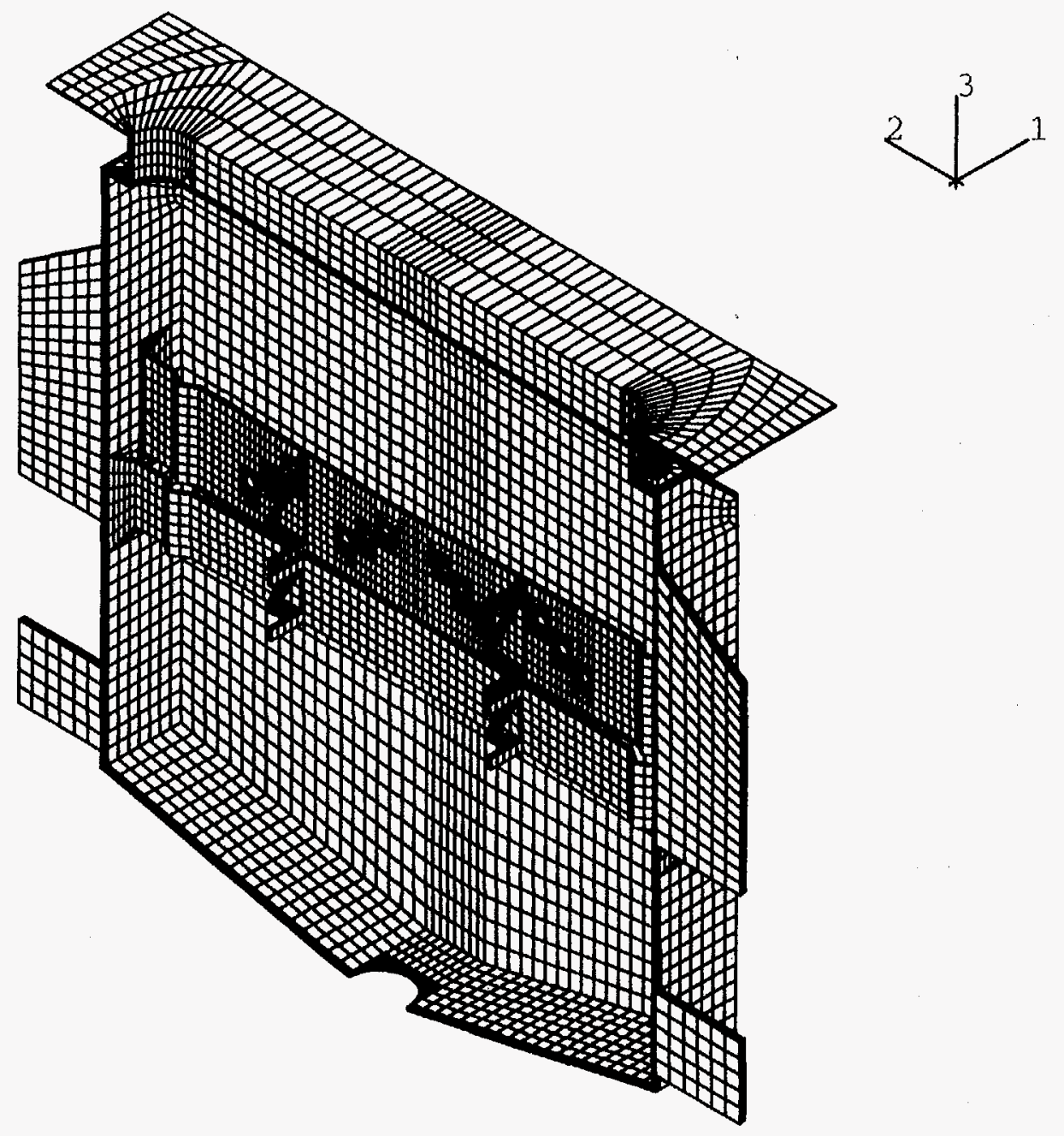

Figure 4-1. Americium/Curium Vitrification Bushing Melter 2A

Finite Element Analysis Mesh 


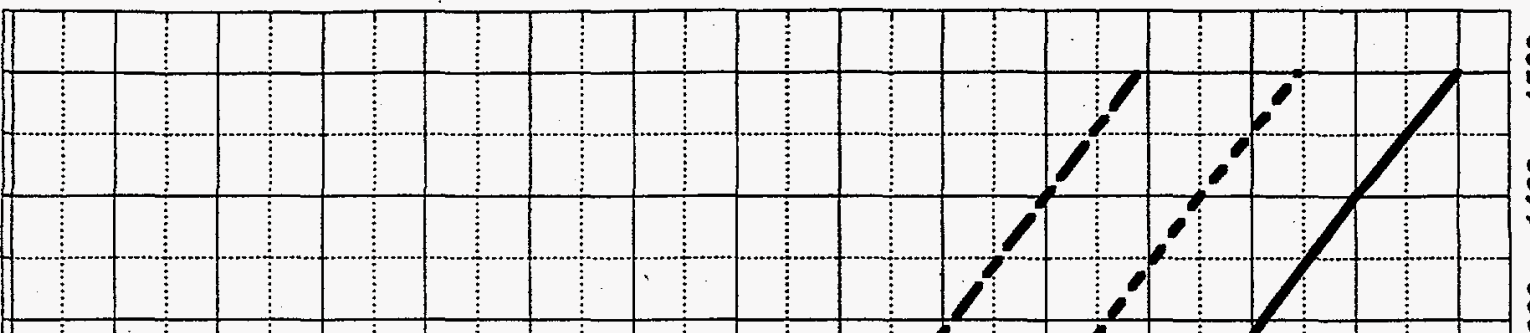

논

8

욤

ฐิ

욤

용

के
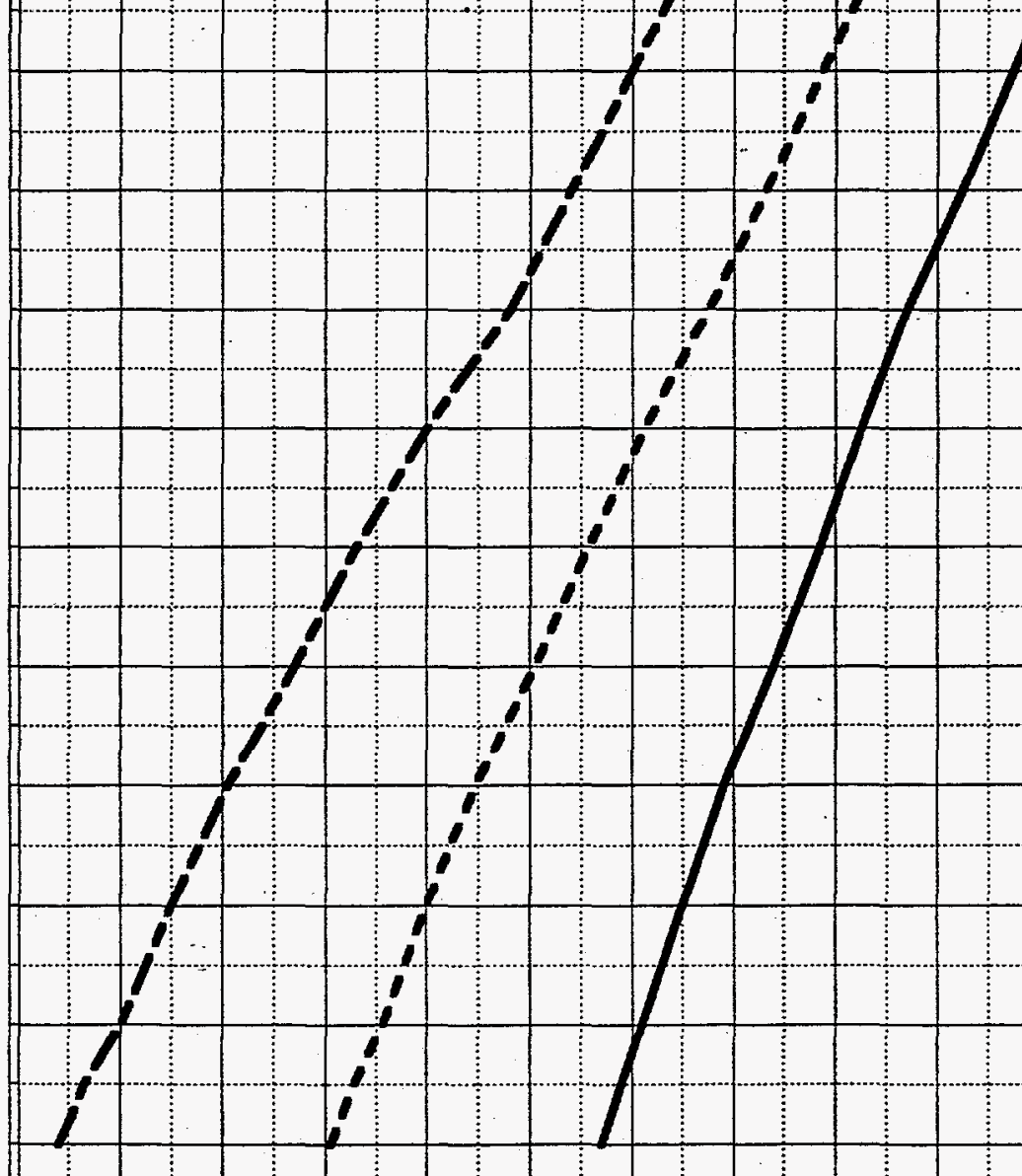

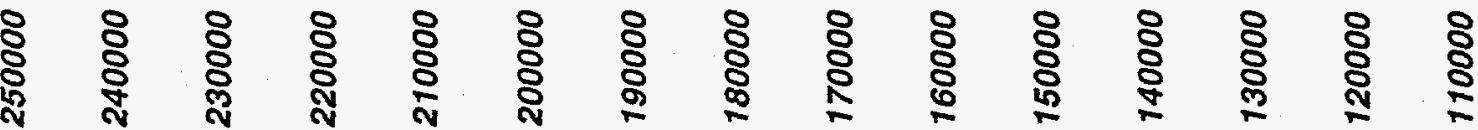

원

8

- 28.2

는접

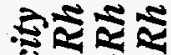

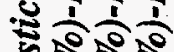

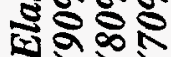

旅衣

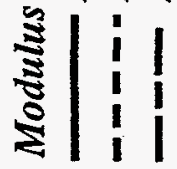

(ndW) XLIDILSVT⿱ до SATALOW 


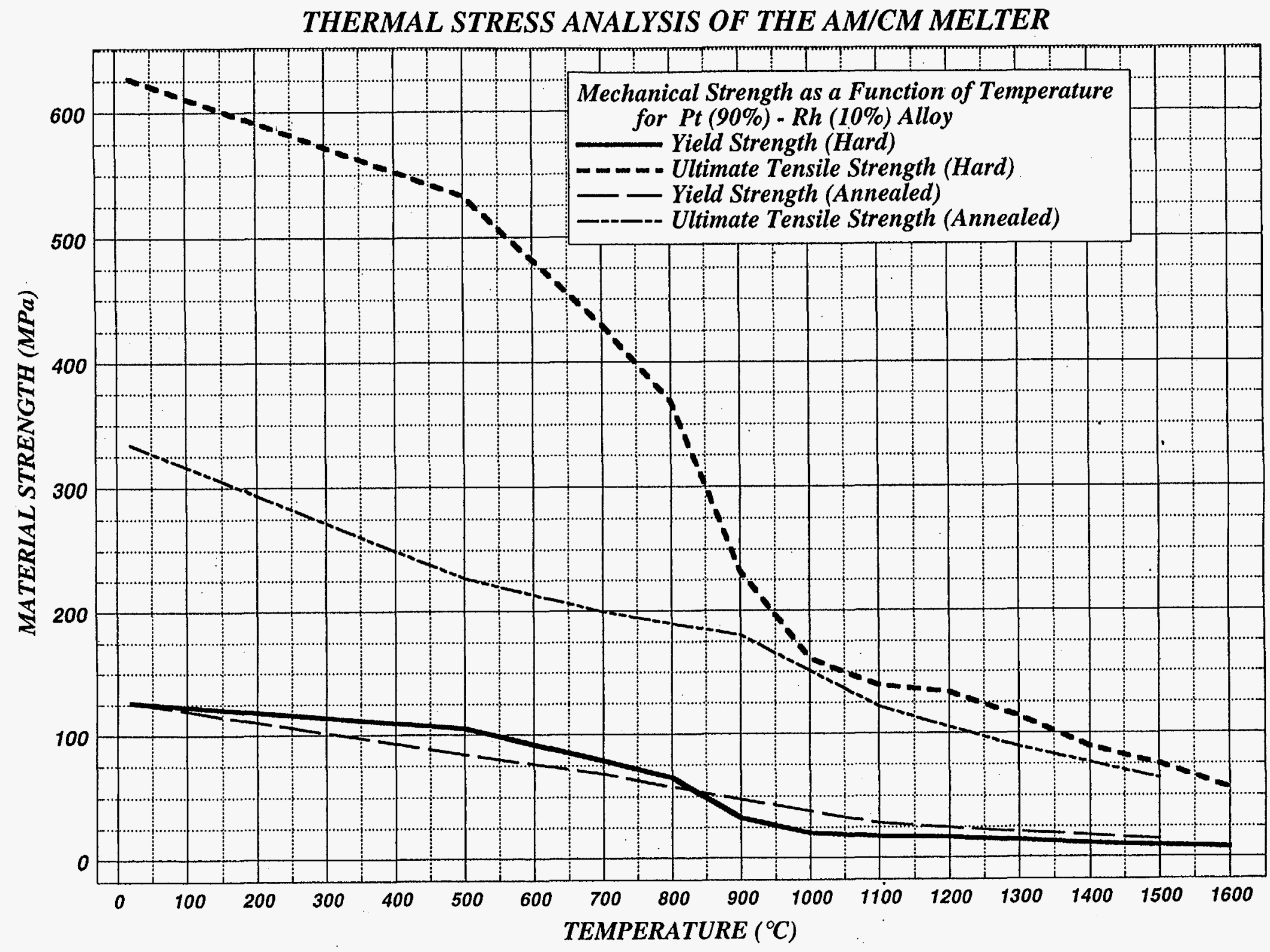

Figure 5-2. The Yield \& Ultimate Strength of the Platinum (90\%)-Rhodium (10\%) Alloy 
THERMAL STRESS ANALYSIS OF THE AM/CM MELTER

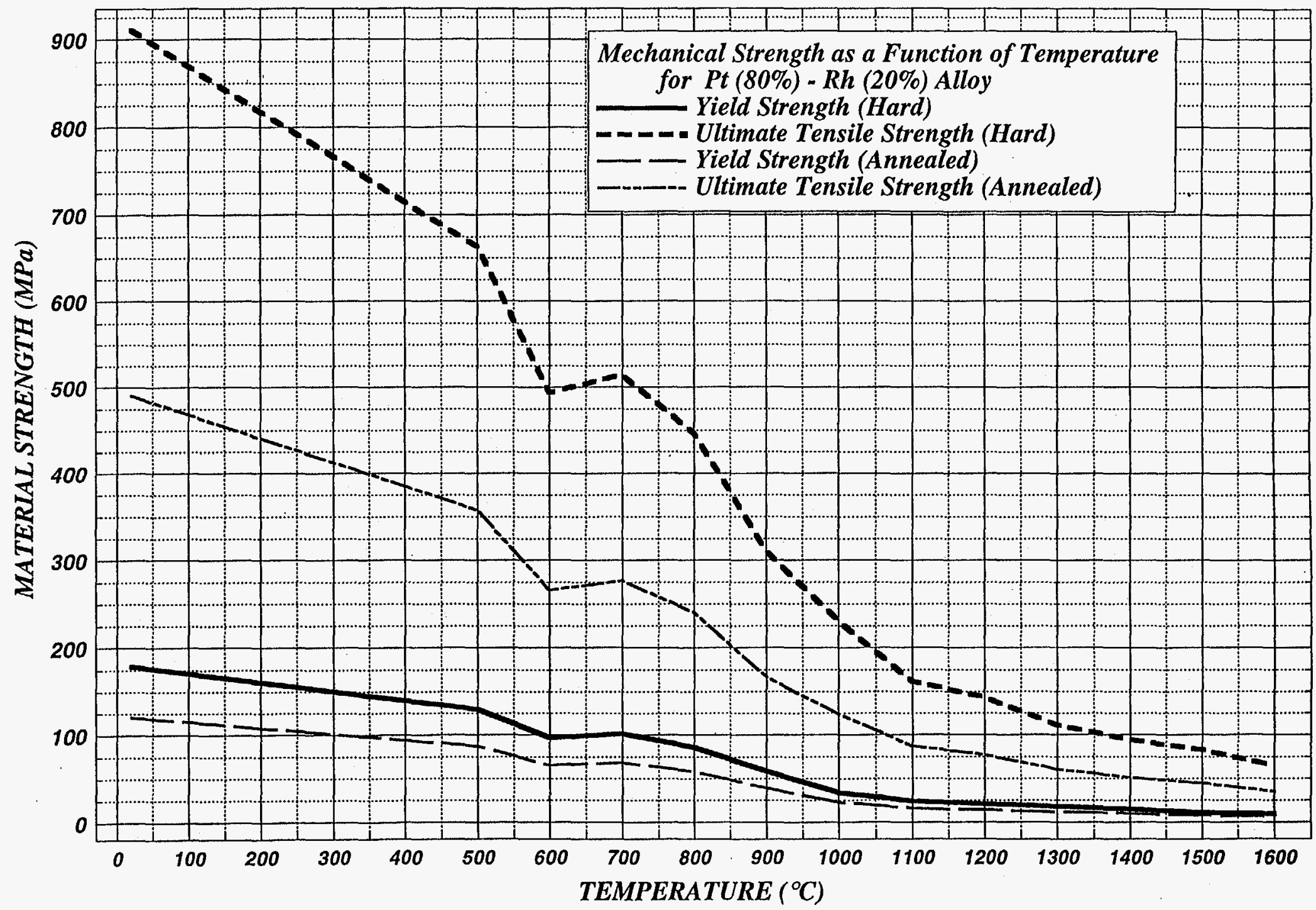

Figure 5-3. The Yield \& Ultimate Strength of the Platinum (80\%)-Rhodium (20\%) Alloy 


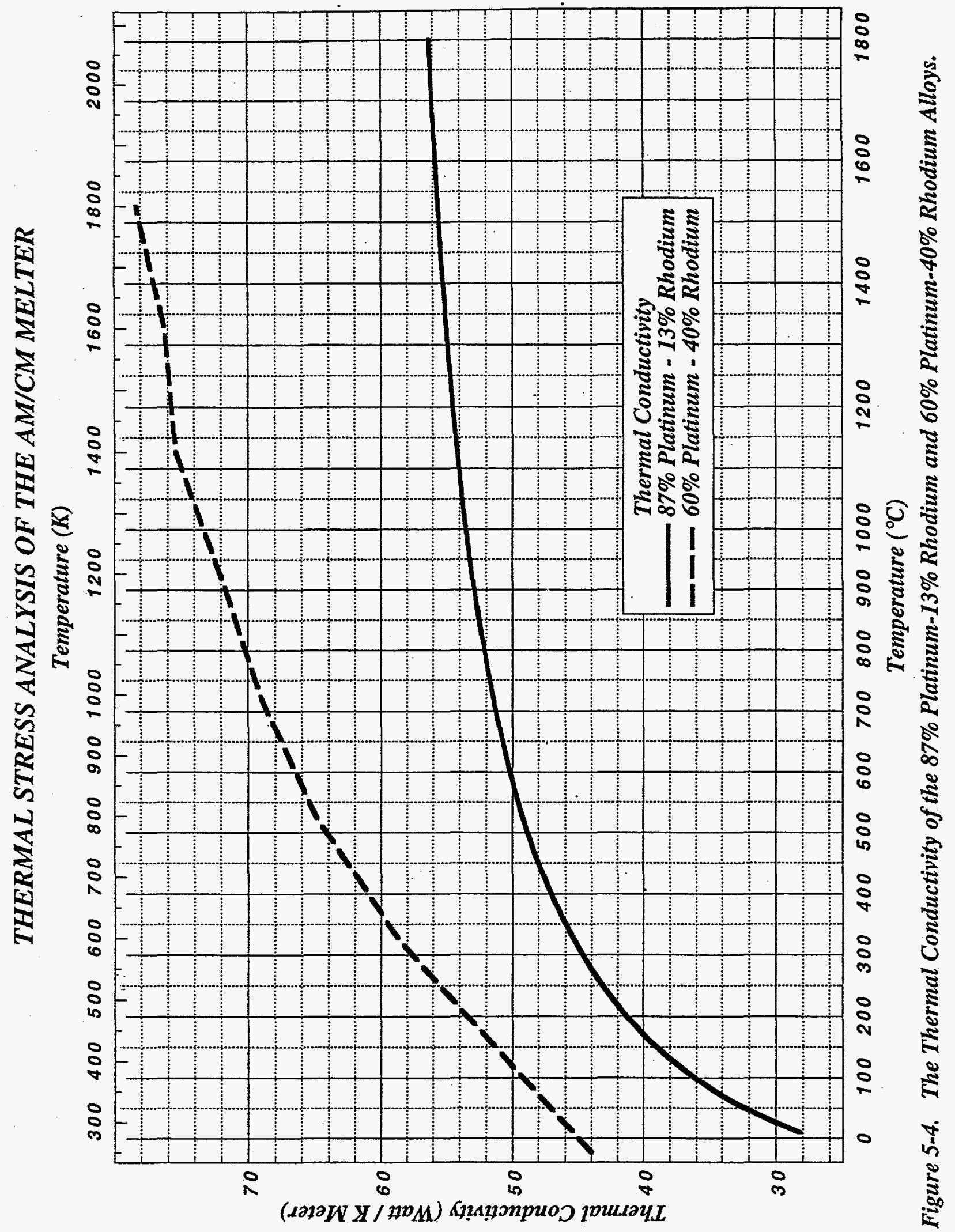




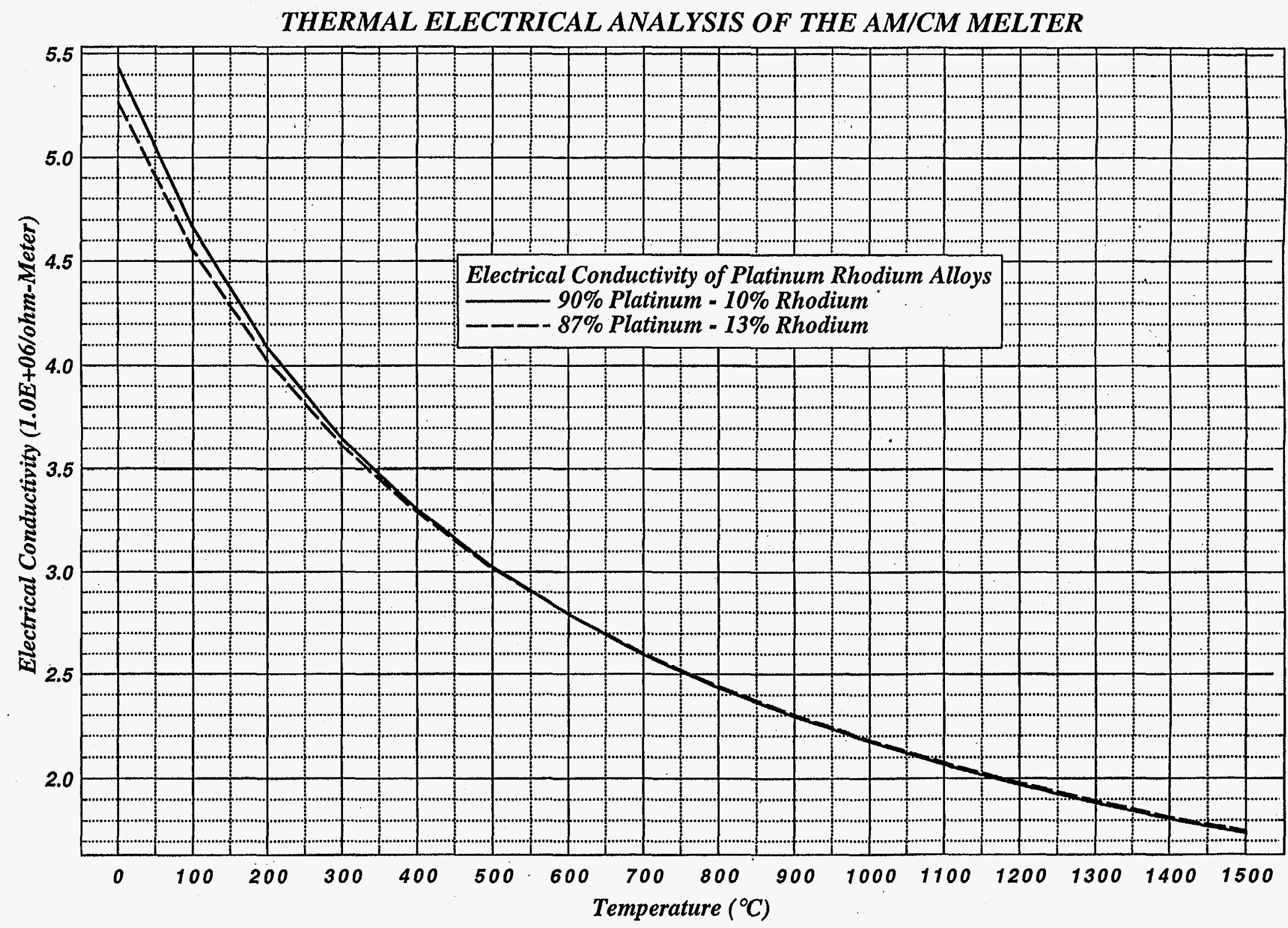

Figure 5-5. The Electrical Conductivity of the 90\% Platinum-10\% Rhodium and 87\% Platinum-13\% Rhodium Alloys. 


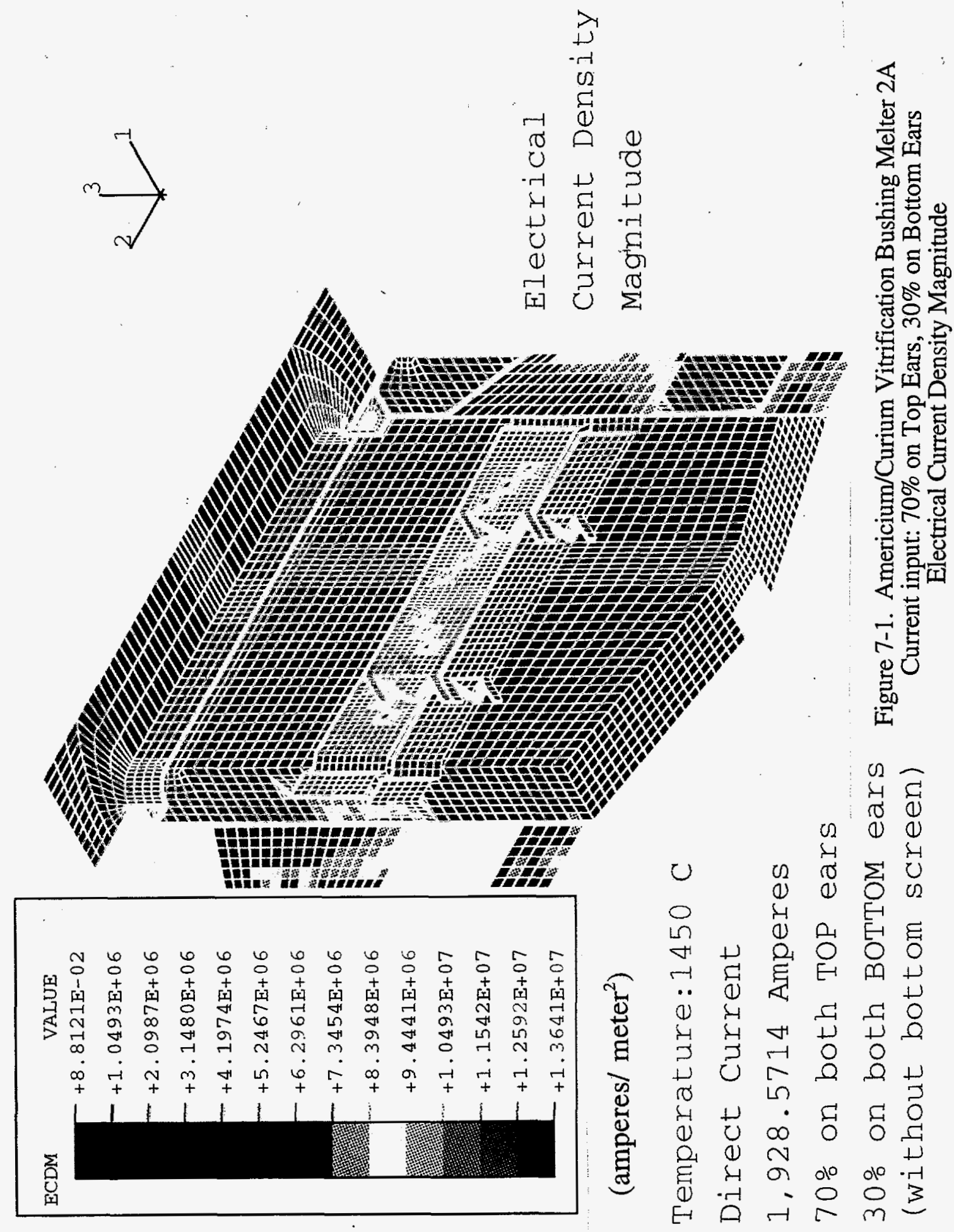




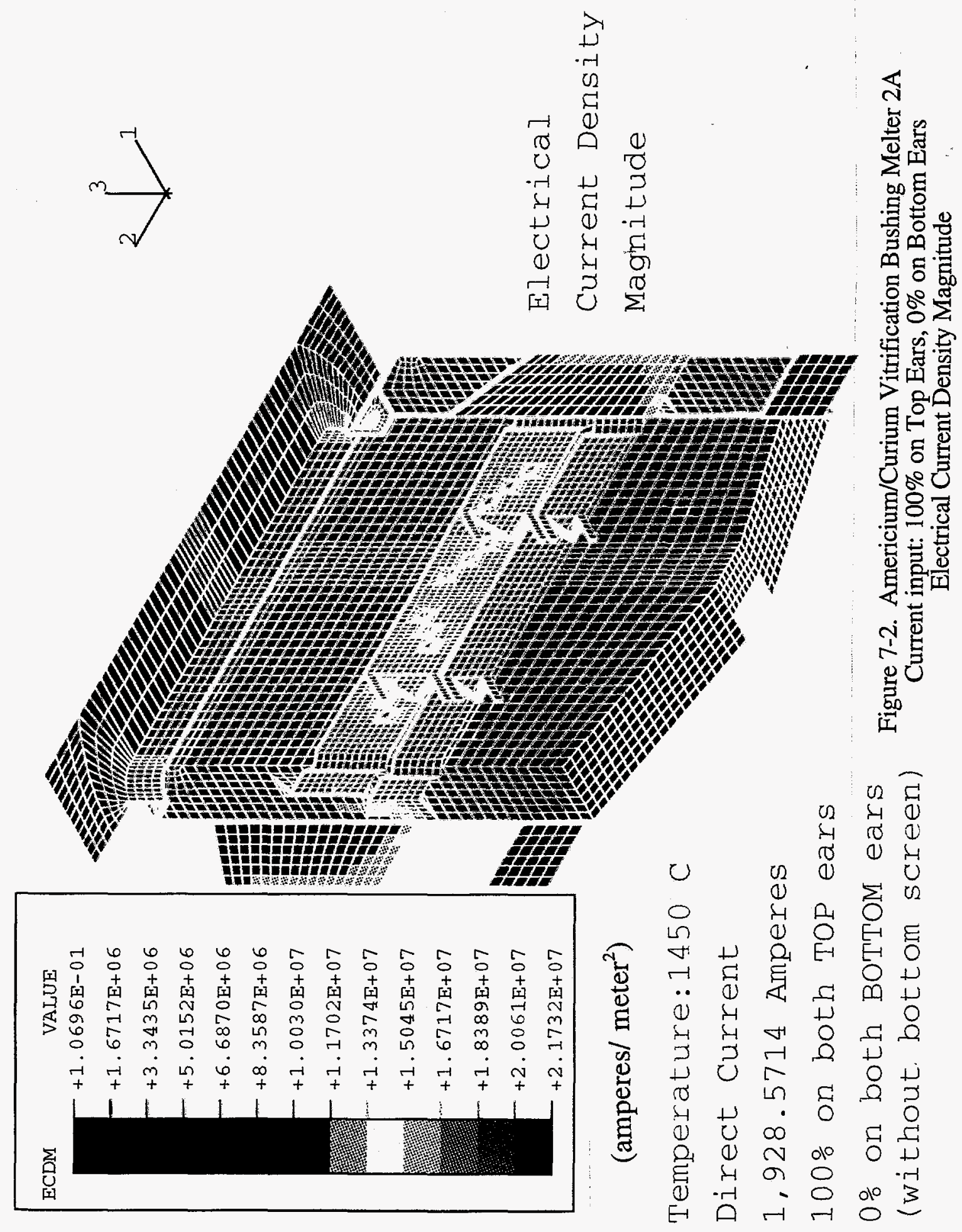



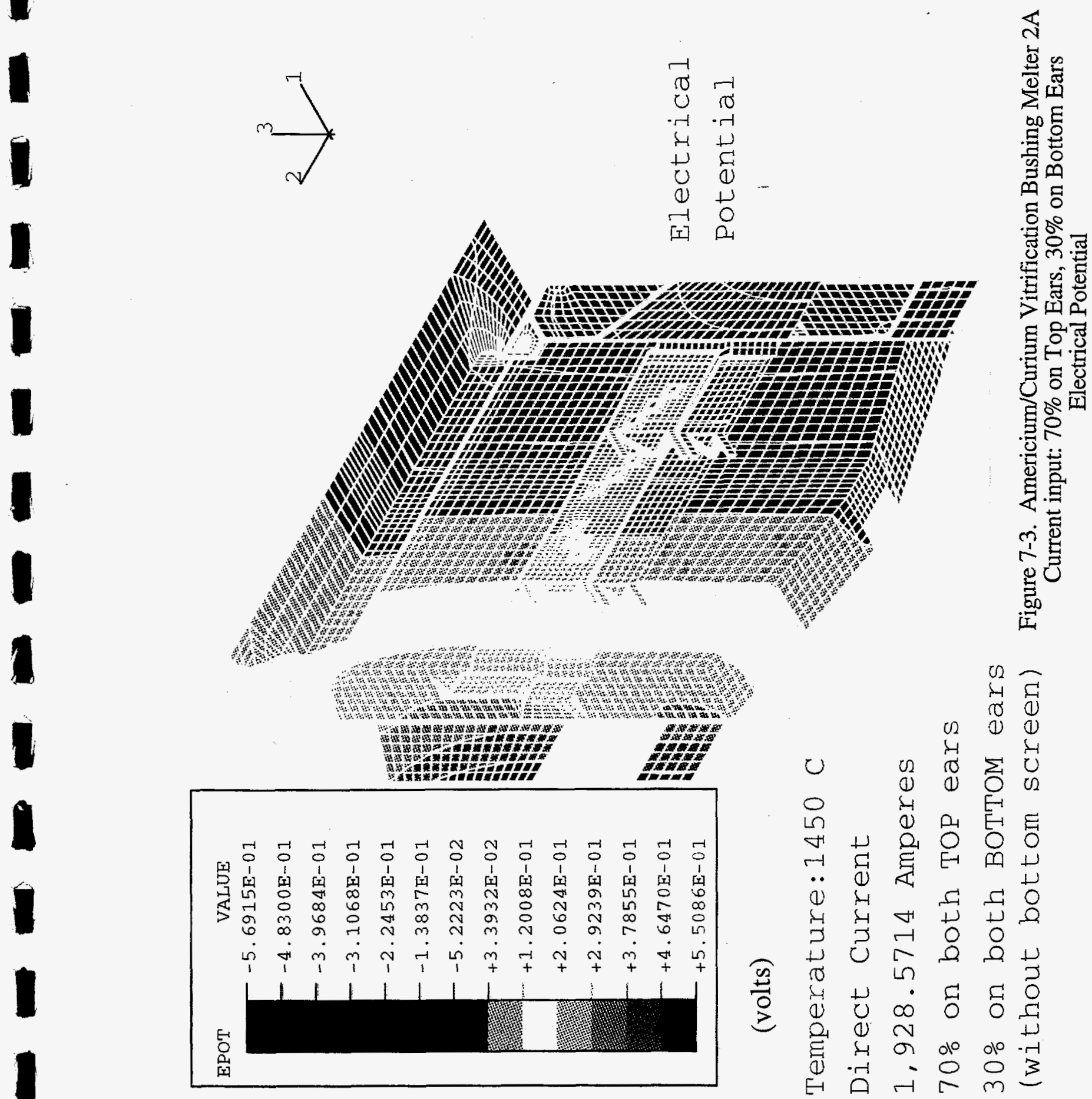

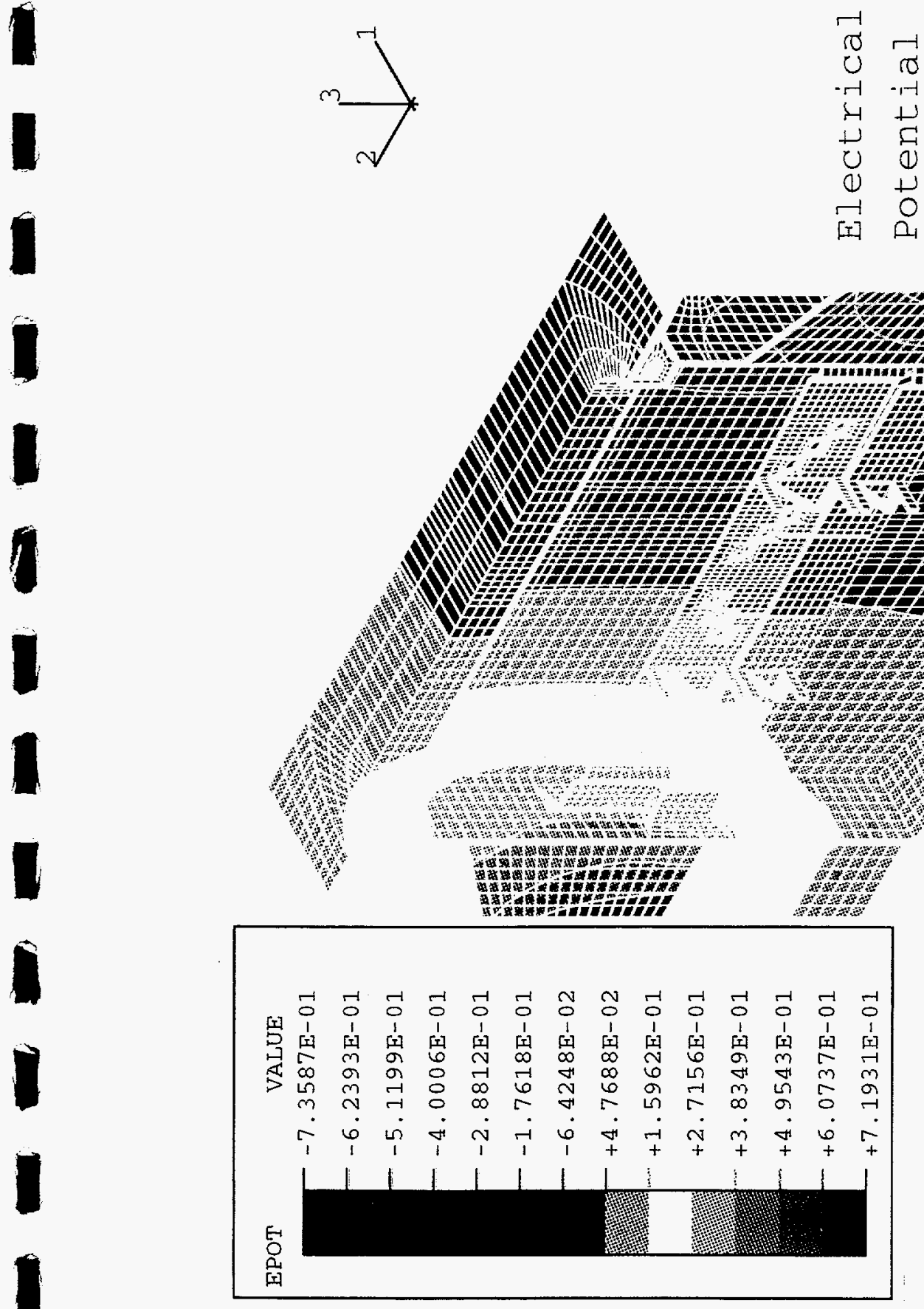

$\overleftrightarrow{4}$

造的

$\sum_{0}$

章

คิ

동ㅇㅇㅇ

귱용

蒠

是露

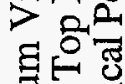

$\int_{-\infty}^{+\infty}$

1

1

1

1

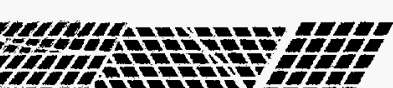

寻它恶

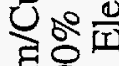

悬

它

$+2=2=$

$\{2=12$

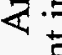

广

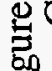

몬 


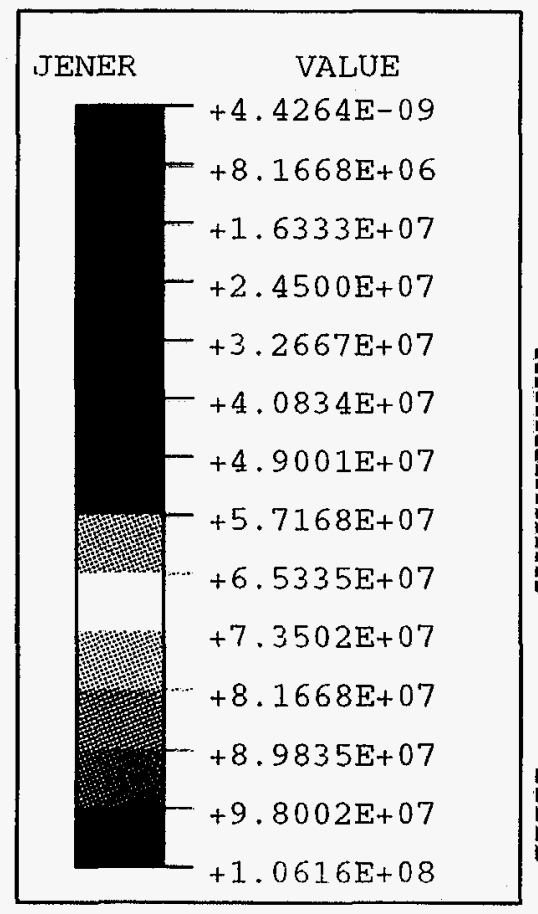

(joules/meter ${ }^{3}$ )

Temperature: 1450

Direct Current

1,928.5714 Amperes

$70 \%$ on both TOP ears

$30 \%$ on both BOTTOM ears (without bottom screen)

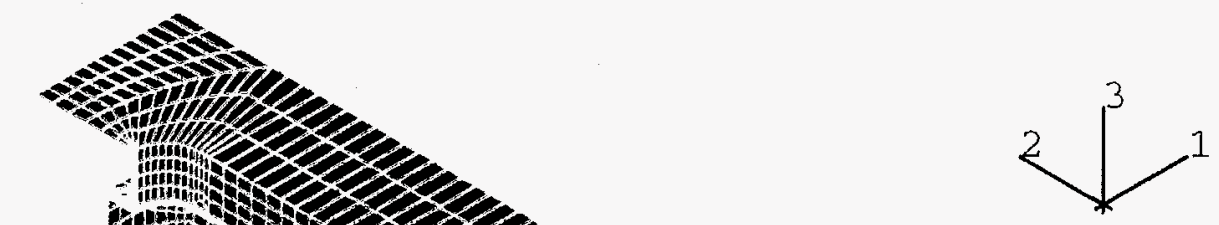

Electrical

Energy Dissipated per unit volume

Figure 7-5. Americium/Curium Vitrification Bushing Melter 2A Current input: $70 \%$ on Top Ears, 30\% on Bottom Ears Electrical Energy Dissipated per unit volume 


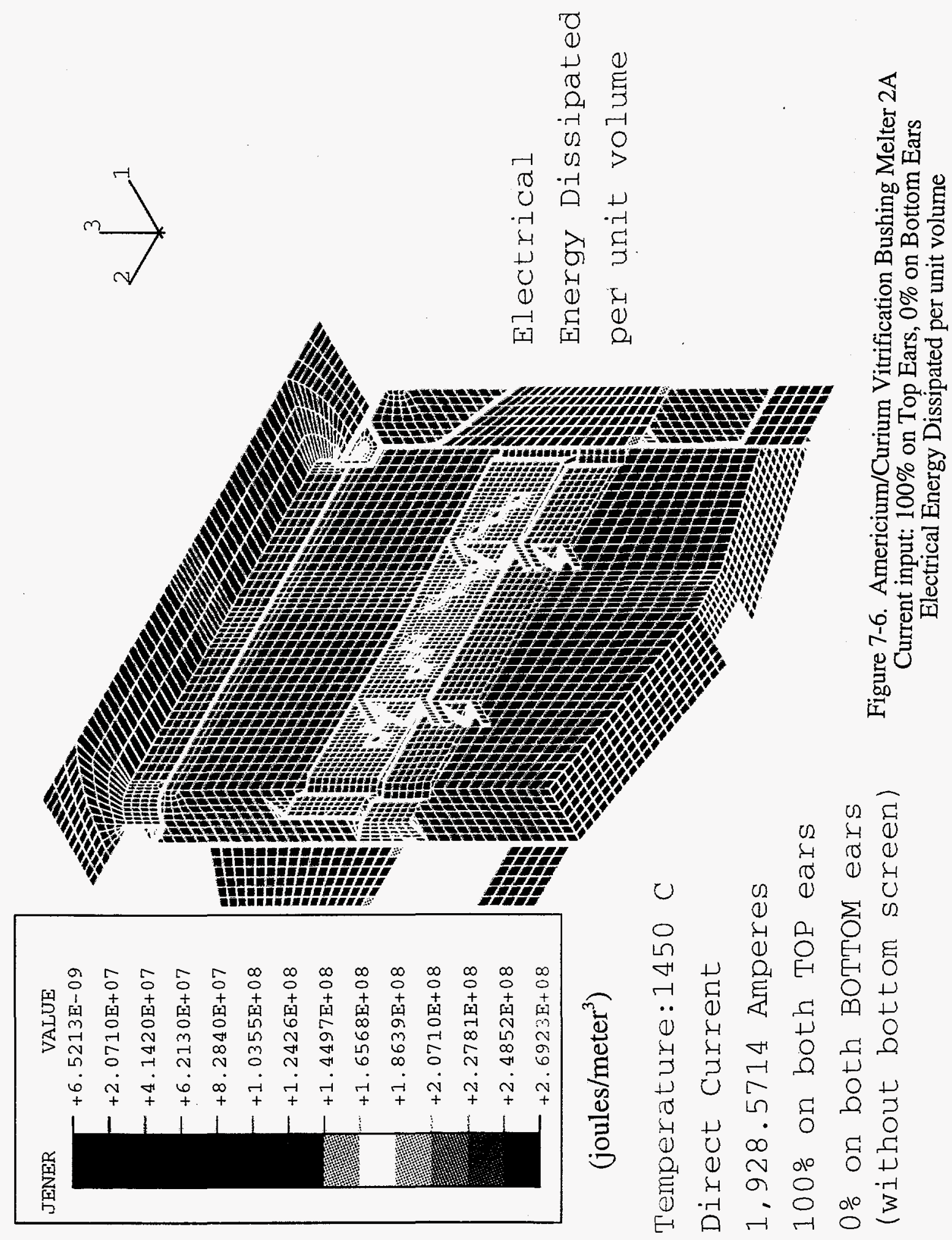




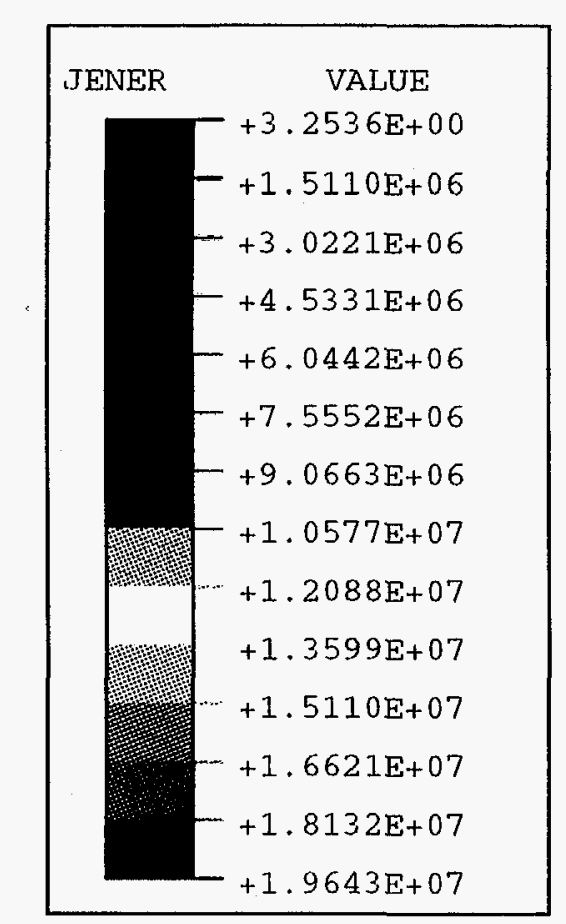

(joules/meter ${ }^{3}$ )

Temperature: $1450 \mathrm{C}$ Direct Current

1,928.5714 Amperes

$70 \%$ on both TOP ears

$30 \%$ on both BOTTOM ears (without bottom screen)

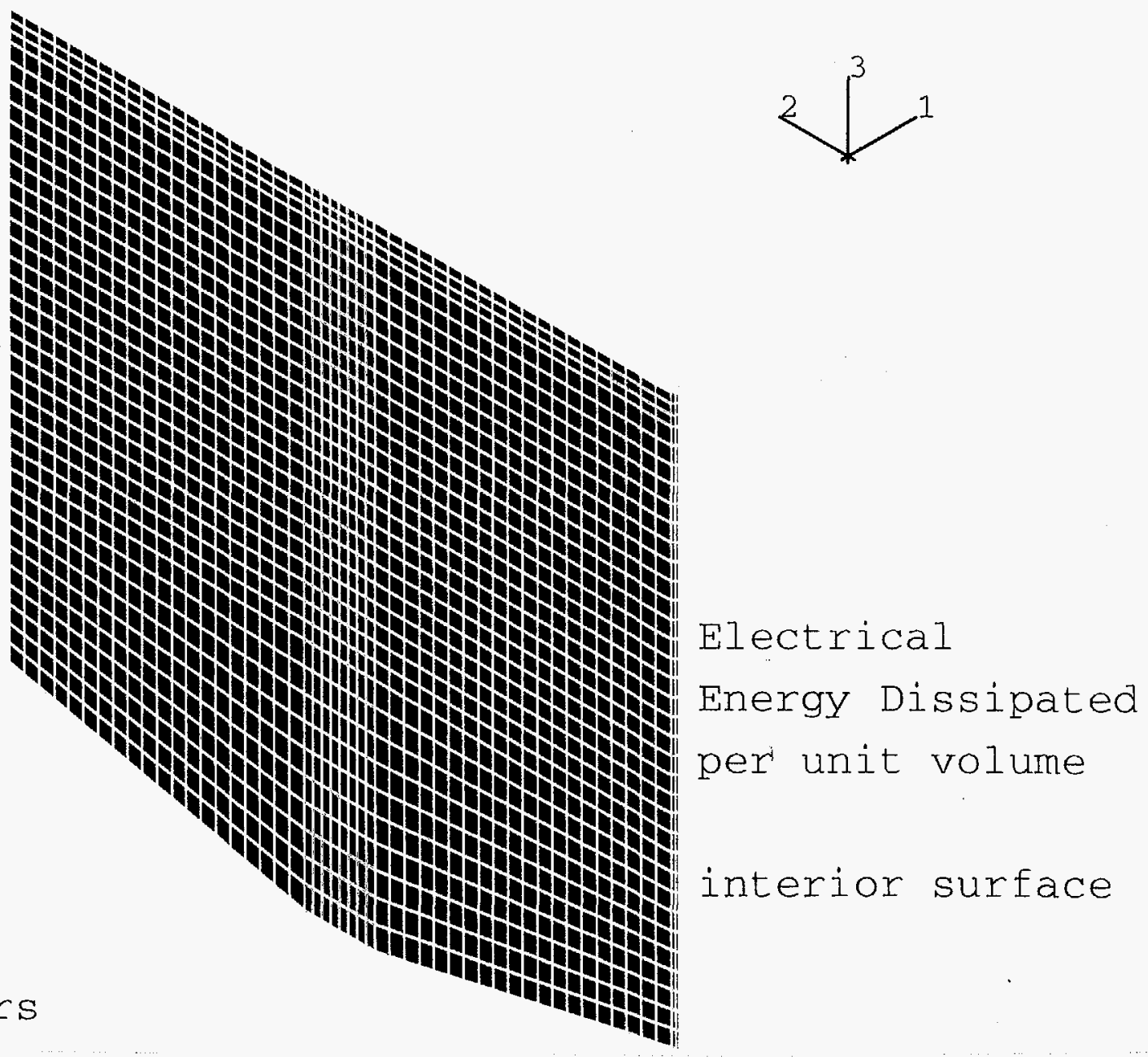

Figure 7-7. Americium/Curium Vitrification Bushing Melter 2A Current input: $70 \%$ on Top Ears, $30 \%$ on Bottom Ears Electrical Energy Dissipated per unit volume in Large Plate 


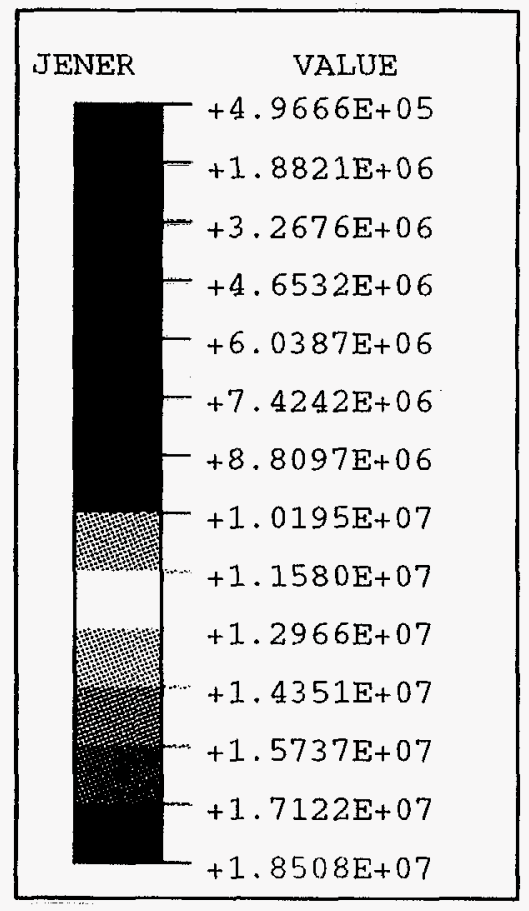

(joules/meter ${ }^{3}$ )

Temperature: $1450 \mathrm{C}$

\section{Direct Current}

1,928.5714 Amperes

$100 \%$ on both TOP ears

$0 \%$ on both BOTTOM ears

(without bottom screen)



Figure 7-8. Americium/Curium Vitrification Bushing Melter 2A Current input: $100 \%$ on Top Ears, $0 \%$ on Bottom Ears Electrical Energy Dissipated per unit volume in Large Plate 


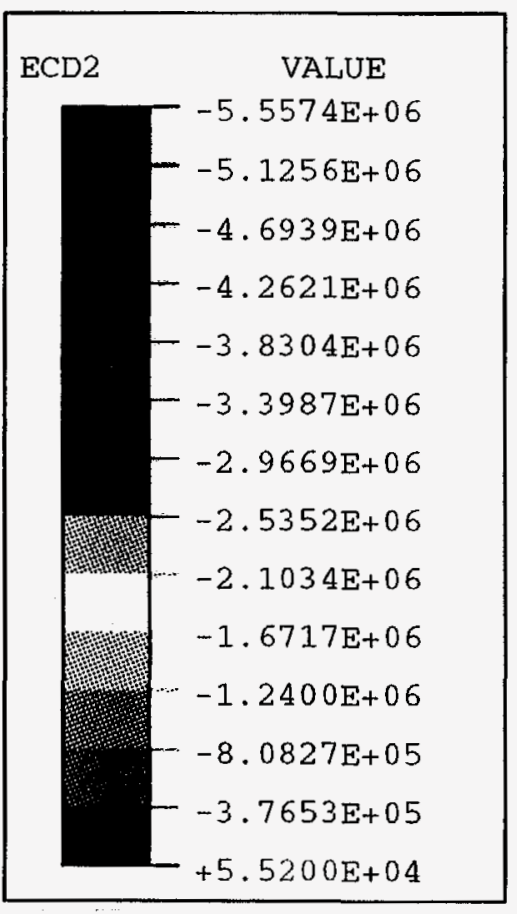

(amperes/ meter ${ }^{2}$ )

Temperature: $1450 \mathrm{C}$ Direct Current

1,928.5714 Amperes

$70 \%$ on both TOP ears

$30 \%$ on both BoTTOM ears (without bottom screen)

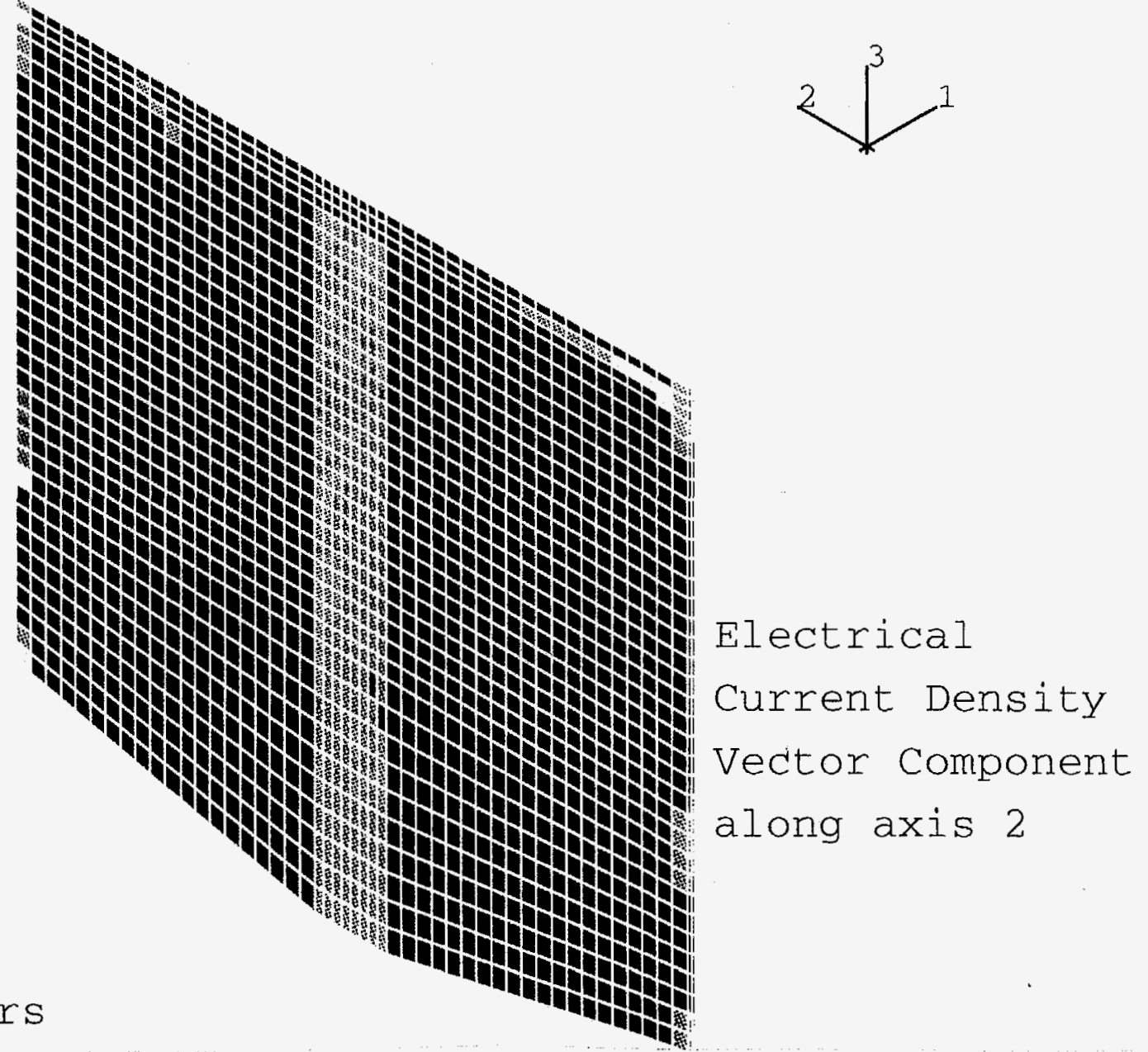

Figure 7-9. Americium/Curium Vitrification Bushing Melter 2A Current input: $70 \%$ on Top Ears, $30 \%$ on Bottom Ears Electrical Current Density Vector $\mathrm{C}_{2}$ in Large Plate 


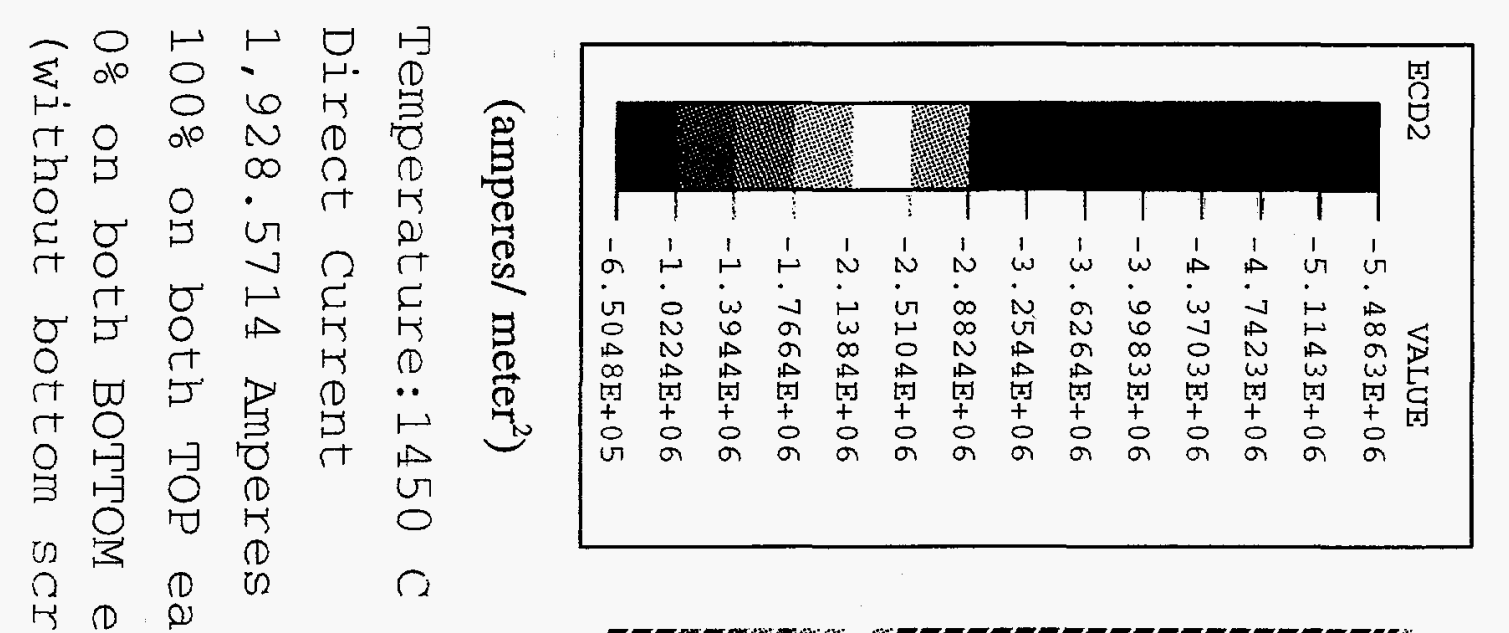

(D) $H$

(D) U

的

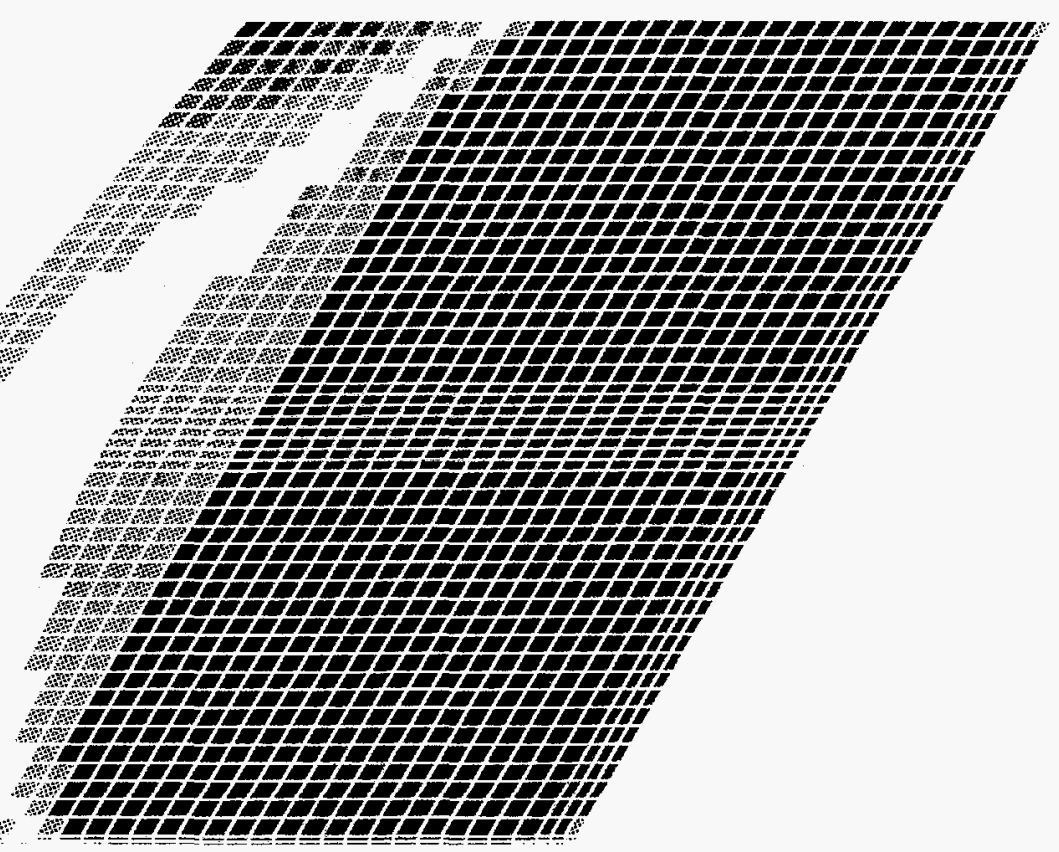

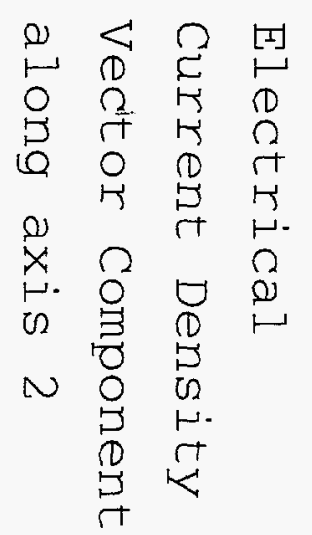

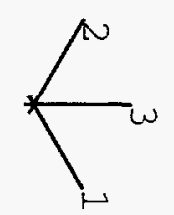




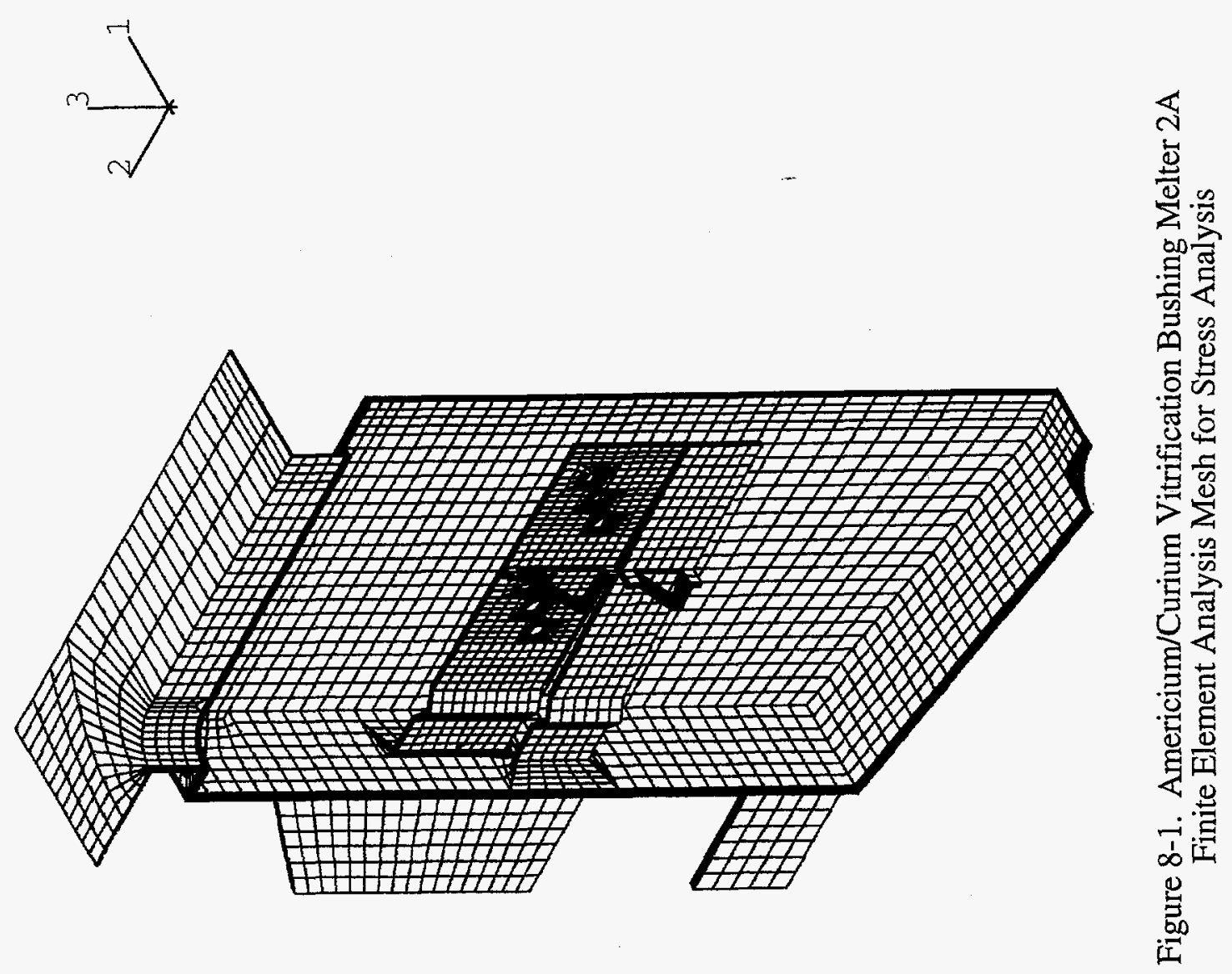




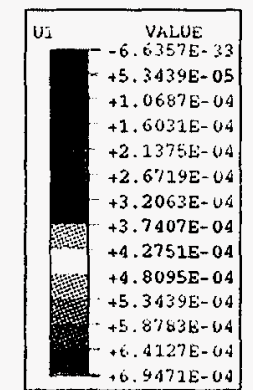

(meters) Temperature

Insulated Sure Insulater simulated with Contact Surfaces Bottom Spring Constant

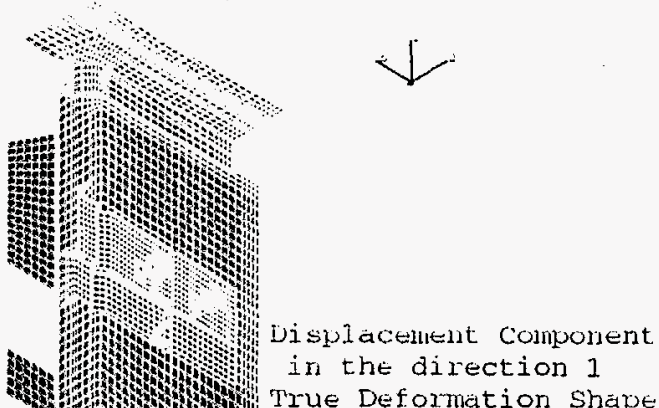
in the direction 1
True Deformation shat $1,453.5457 \mathrm{~N} / \mathrm{M}$

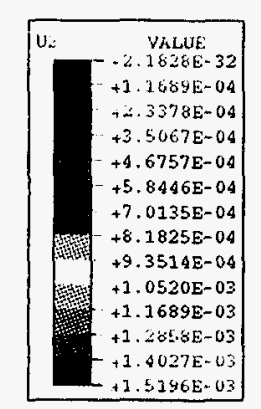

(meters)

I'emperature: 752.550 Insulated Surfaces

are Simulated with

Contact Surfaces

Botcon Spring constant

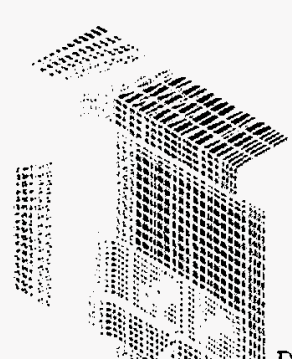

Displacement Component in the direction 2

True Deformation Shape

Figure 8-2. Americium/Curium Vitrification Bushing Melter 2A

Displacement and von Mises Stress Distributions at the Critical Temperature $752.55{ }^{\circ} \mathrm{C}$

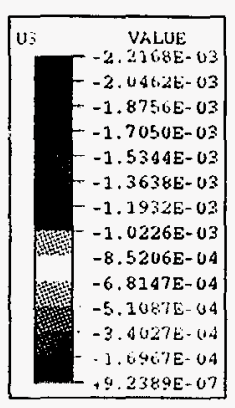

(meters)

Insulated Surfaces

are Simulated with

contact Surfaces

Bottom Spring Constant
$\mathrm{K}=1,453.5457 \mathrm{~N} / \mathrm{M}$

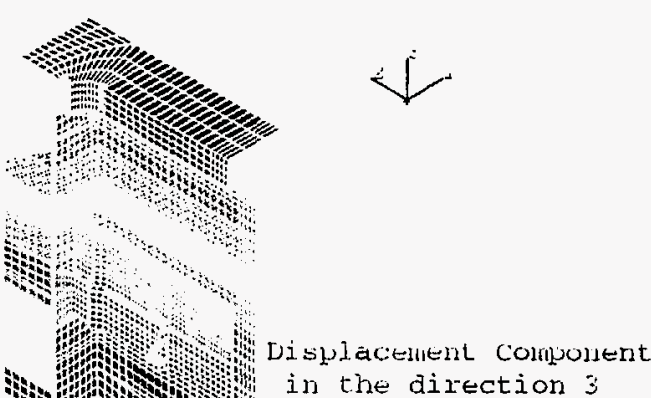

in the direction 3

True Deformation Shape

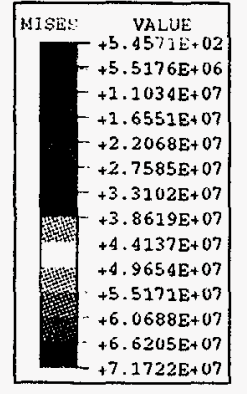

'T'mperäture: 752.55 Insulated Surfaces Simulated with

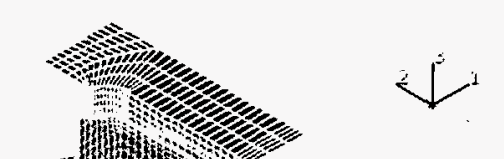

Contact Surfaces

Bottorn Spring Constant

von Máses Stress Contour

True Deformation Shape

(pascals=newtons/meter $\left.{ }^{2}\right)$ 


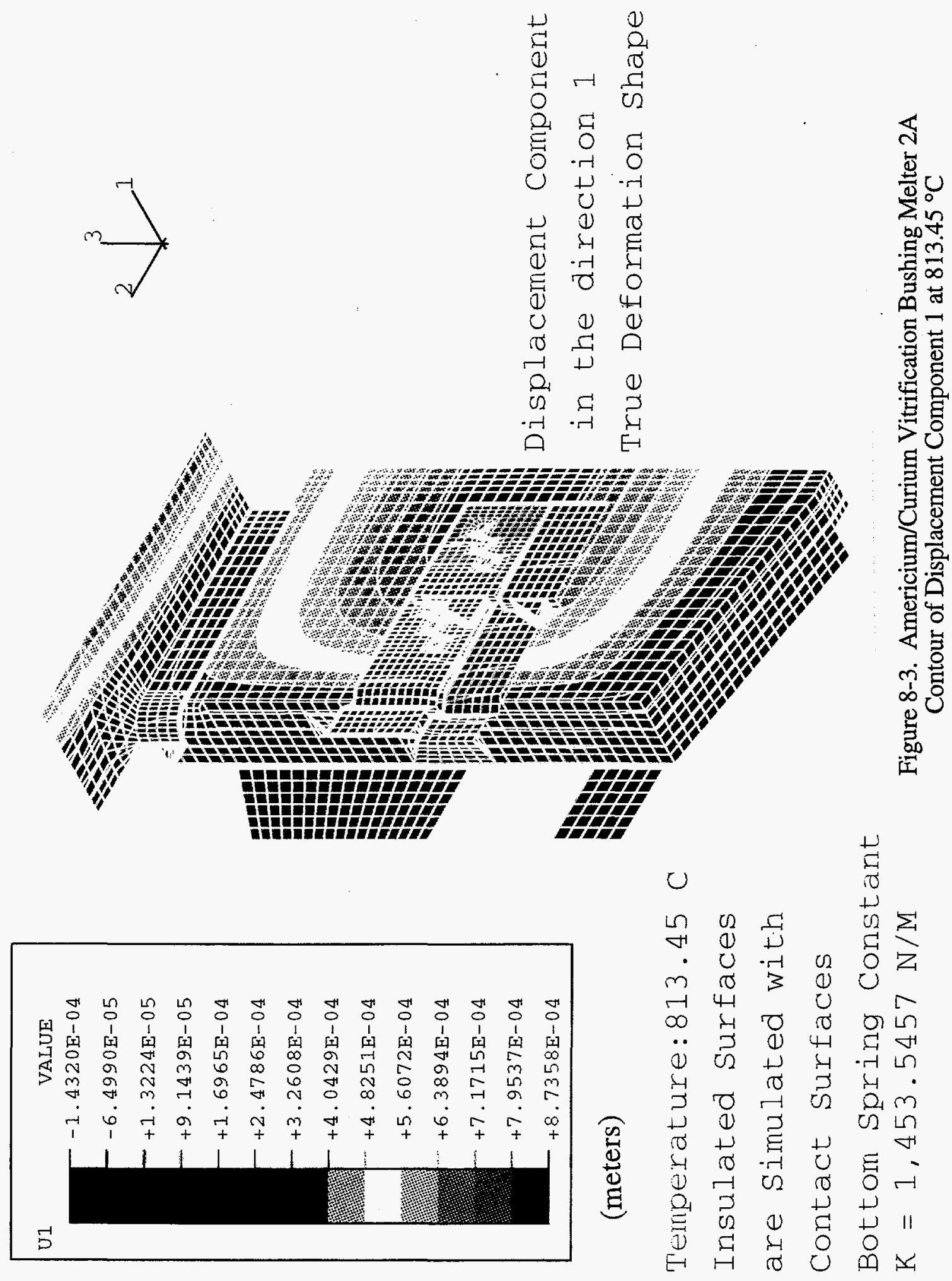




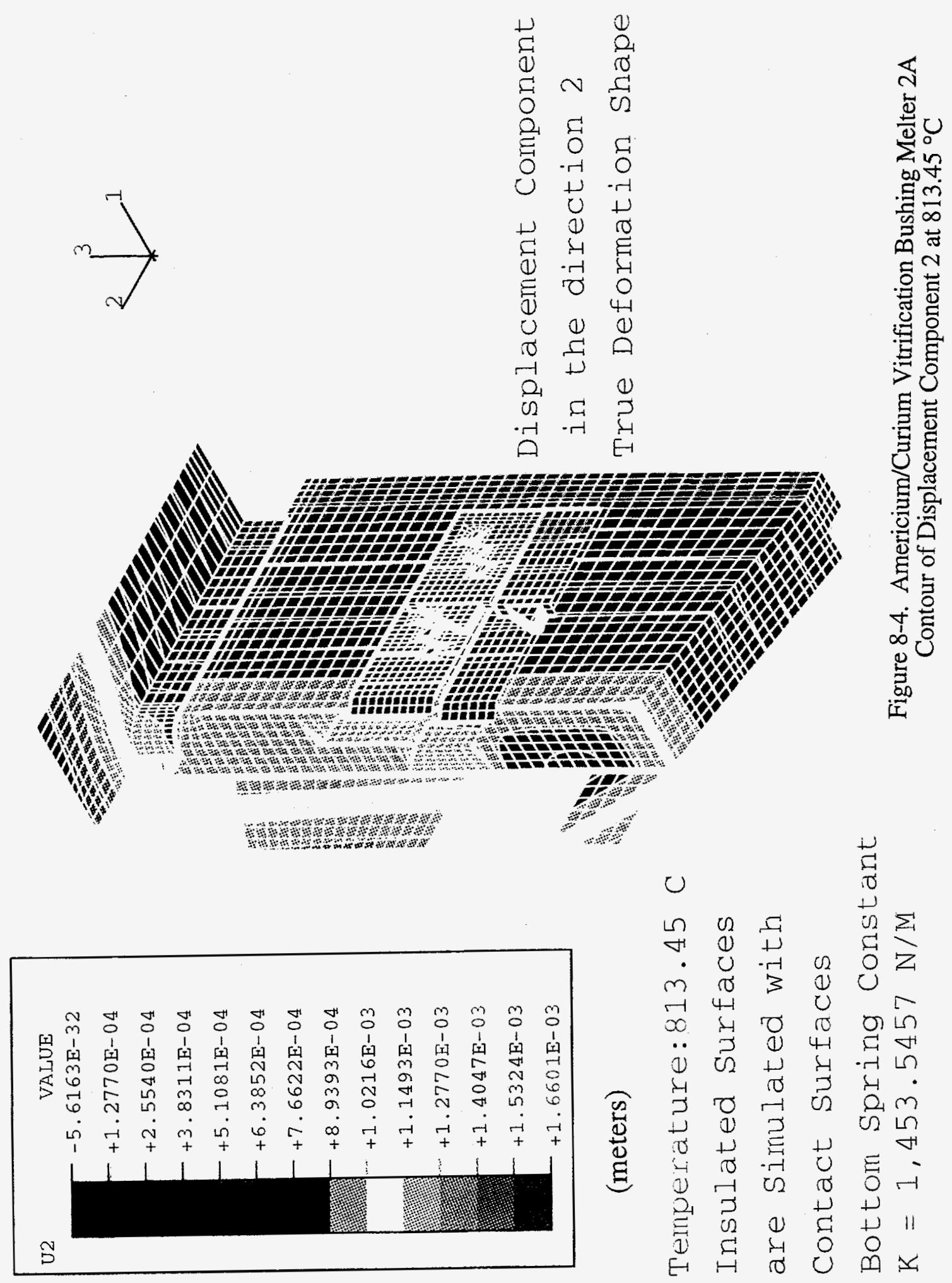




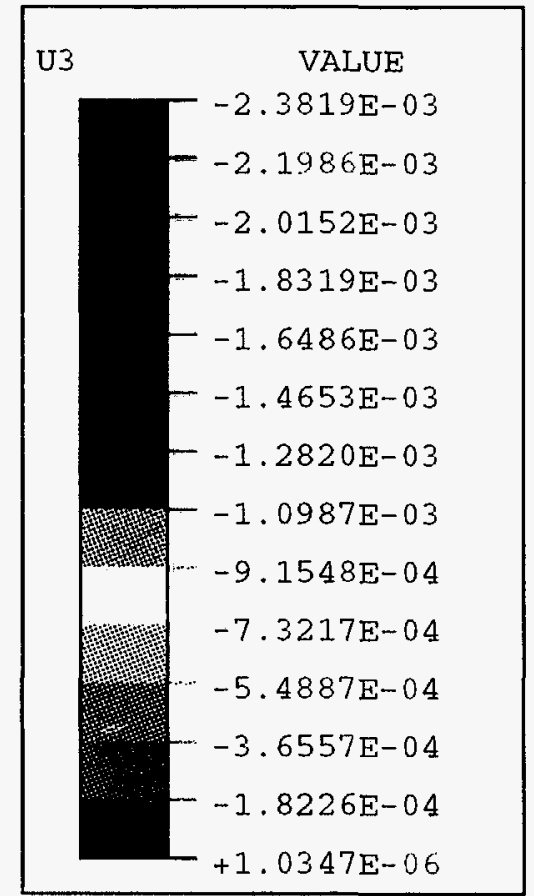

(meters)

Temperature: $813.45 \mathrm{C}$ Insulated Surfaces are Simulated with Contact Surfaces

Bottom Spring Constant $\mathrm{K}=1,453.5457 \mathrm{~N} / \mathrm{M}$

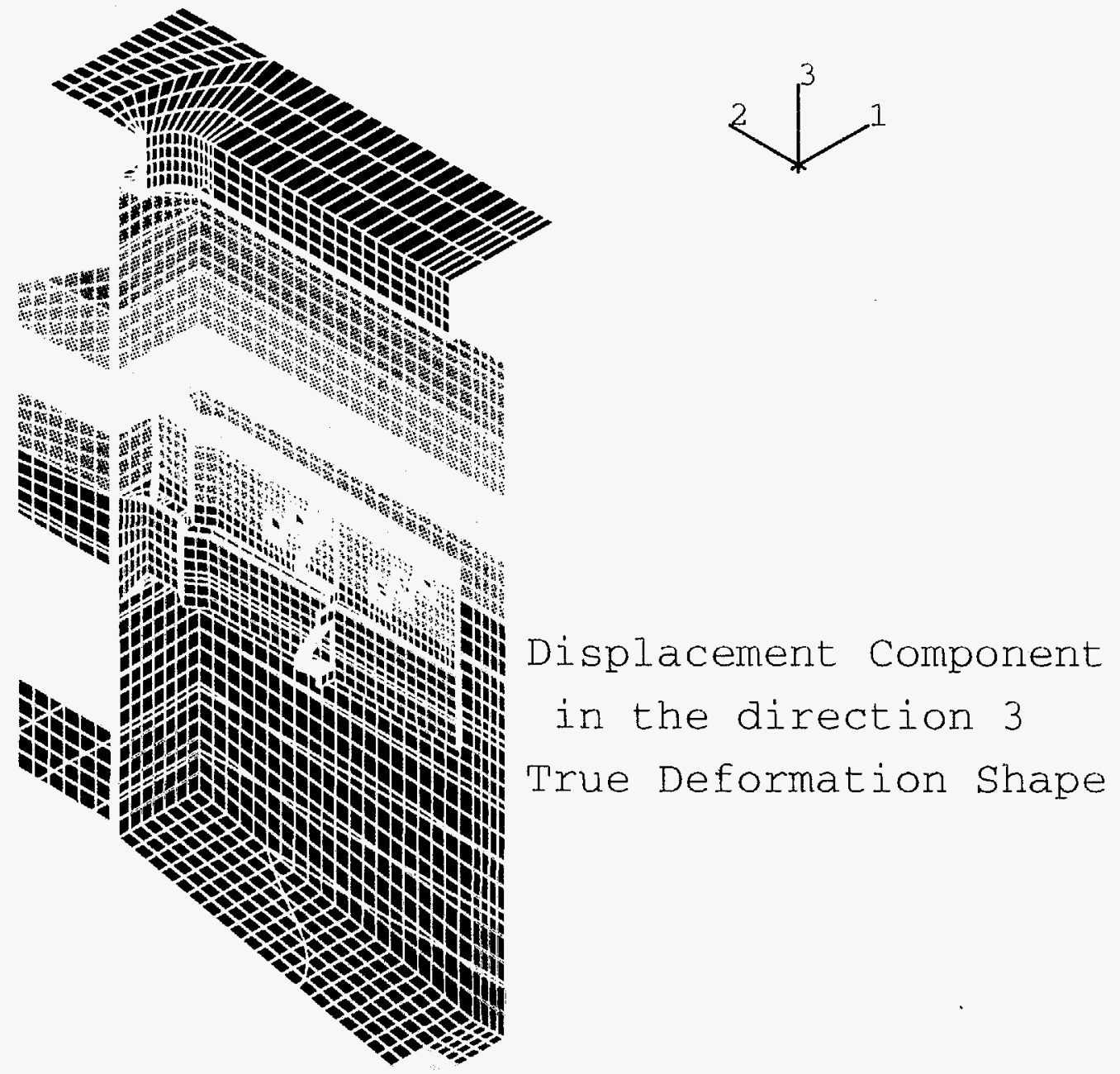

Figure 8-5. Americium/Curium Vitrification Bushing Melter 2A Contour of Displacement Component 3 at $813.45^{\circ} \mathrm{C}$ 

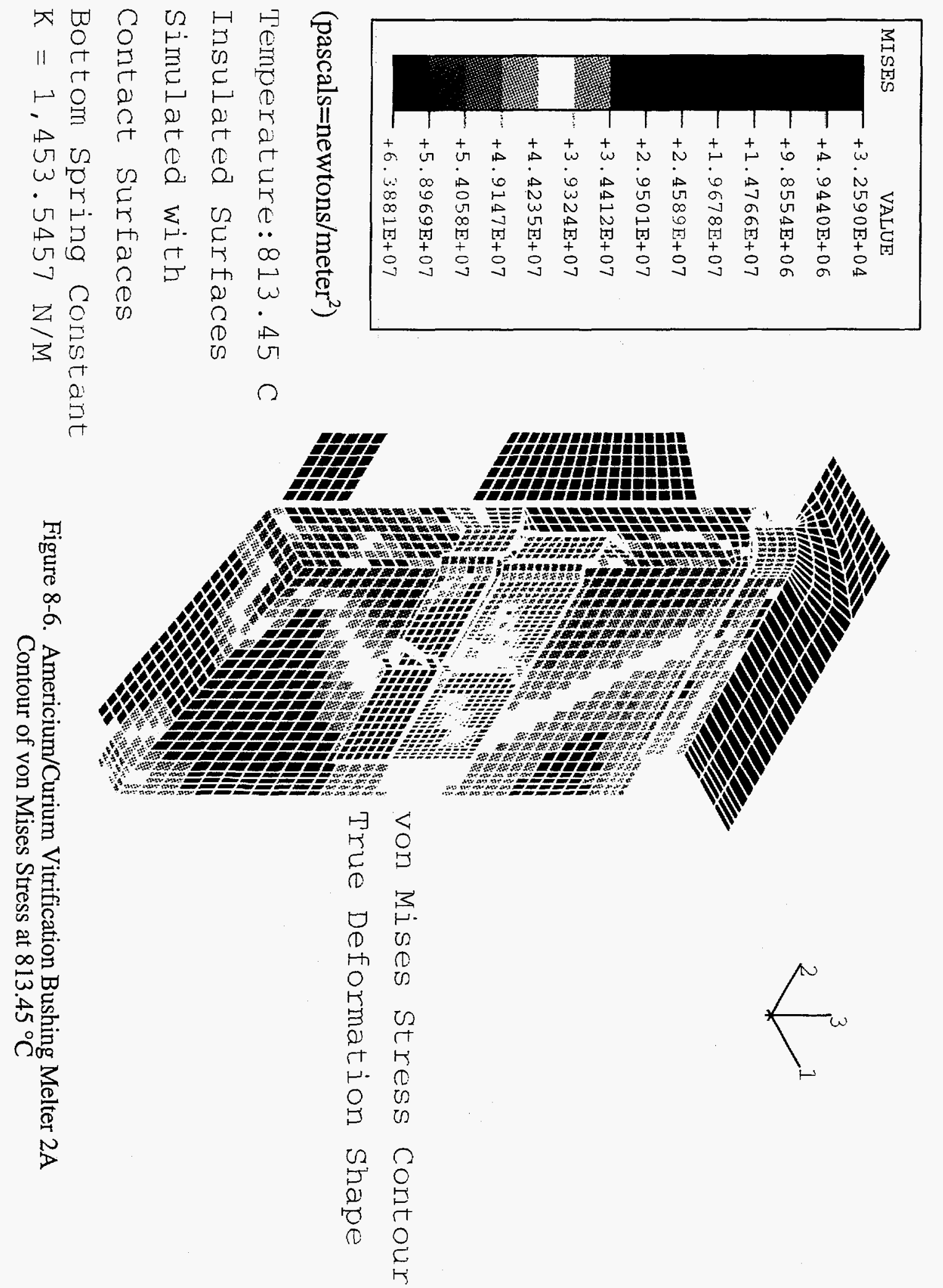

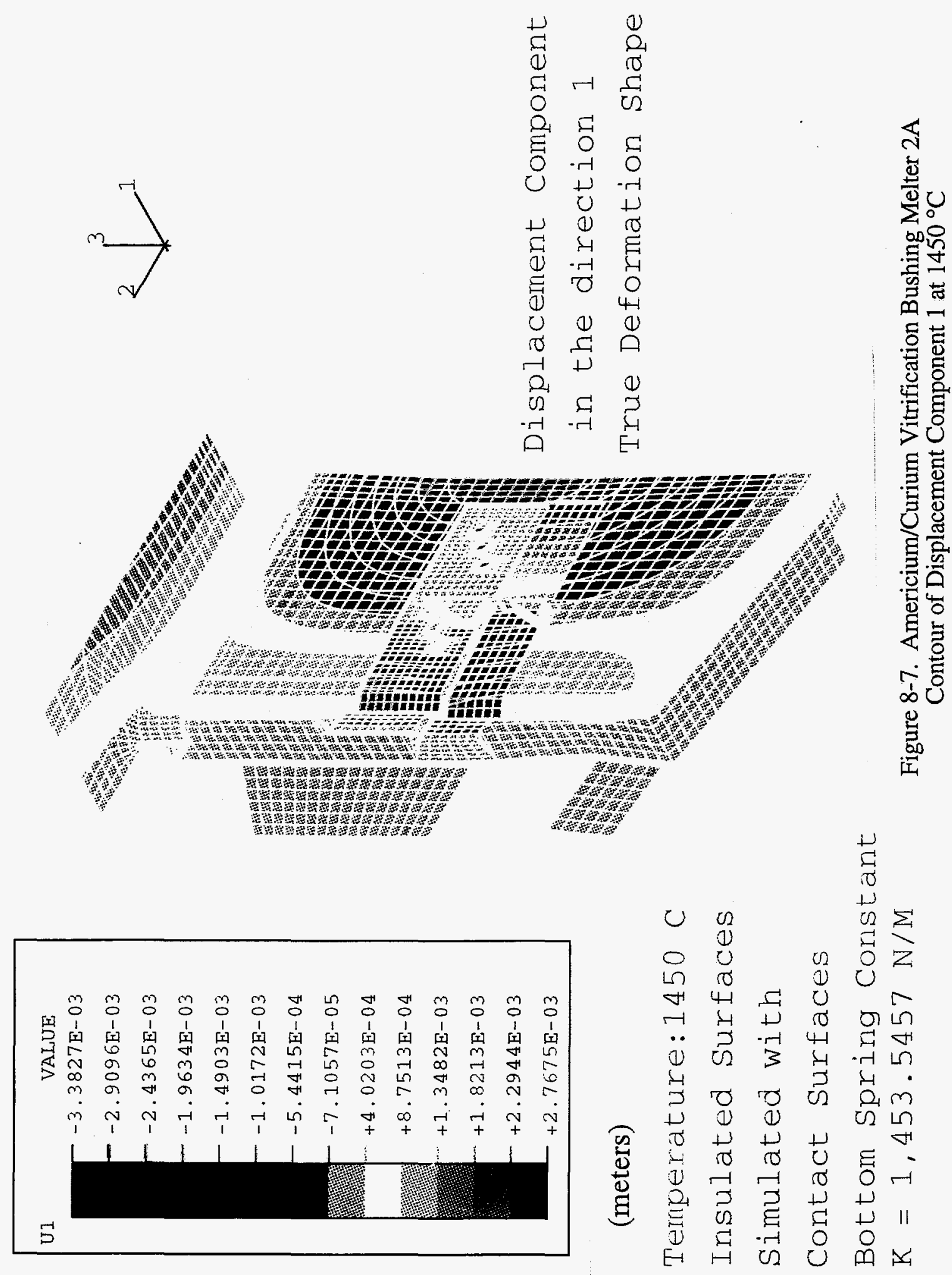

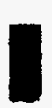




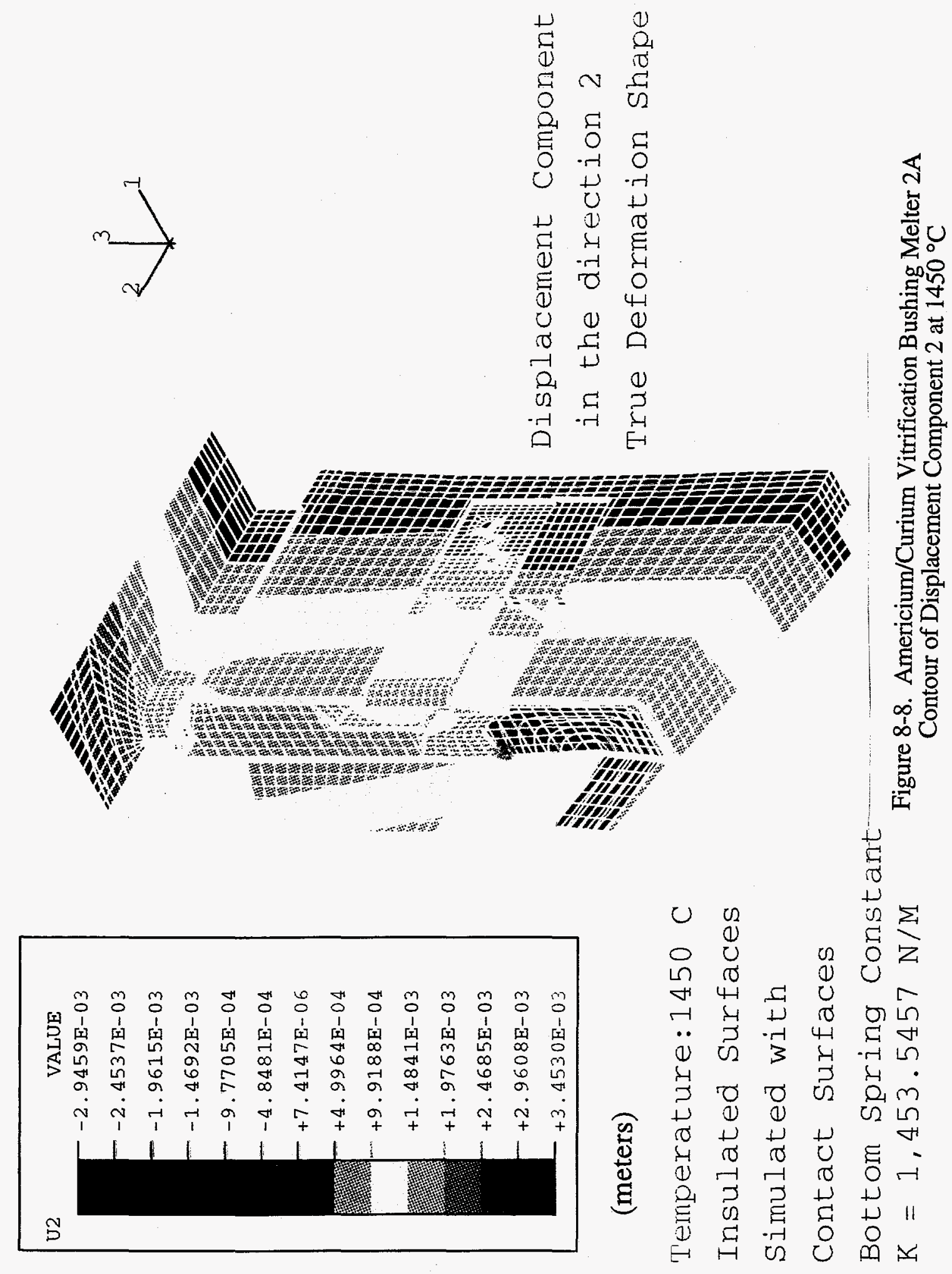




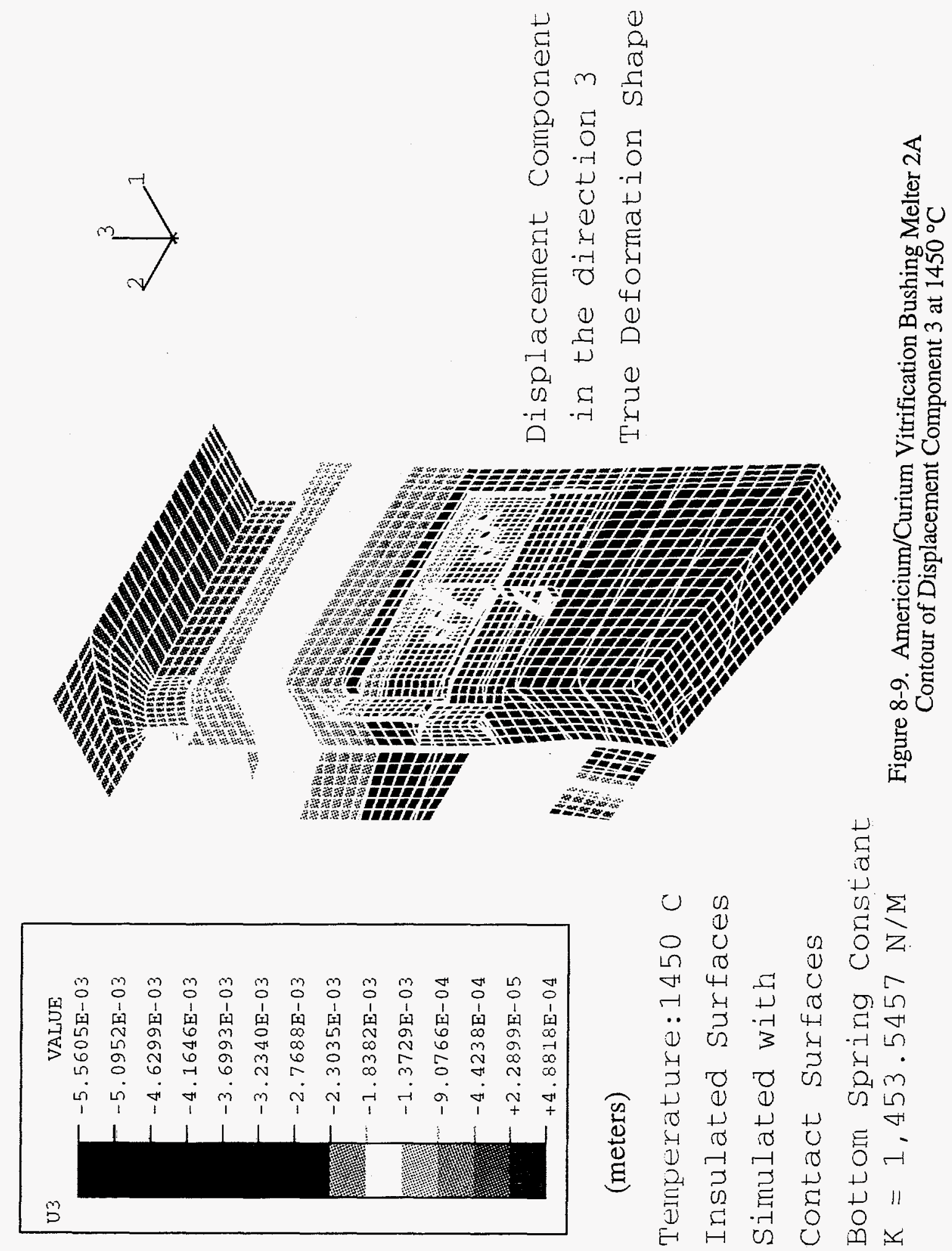



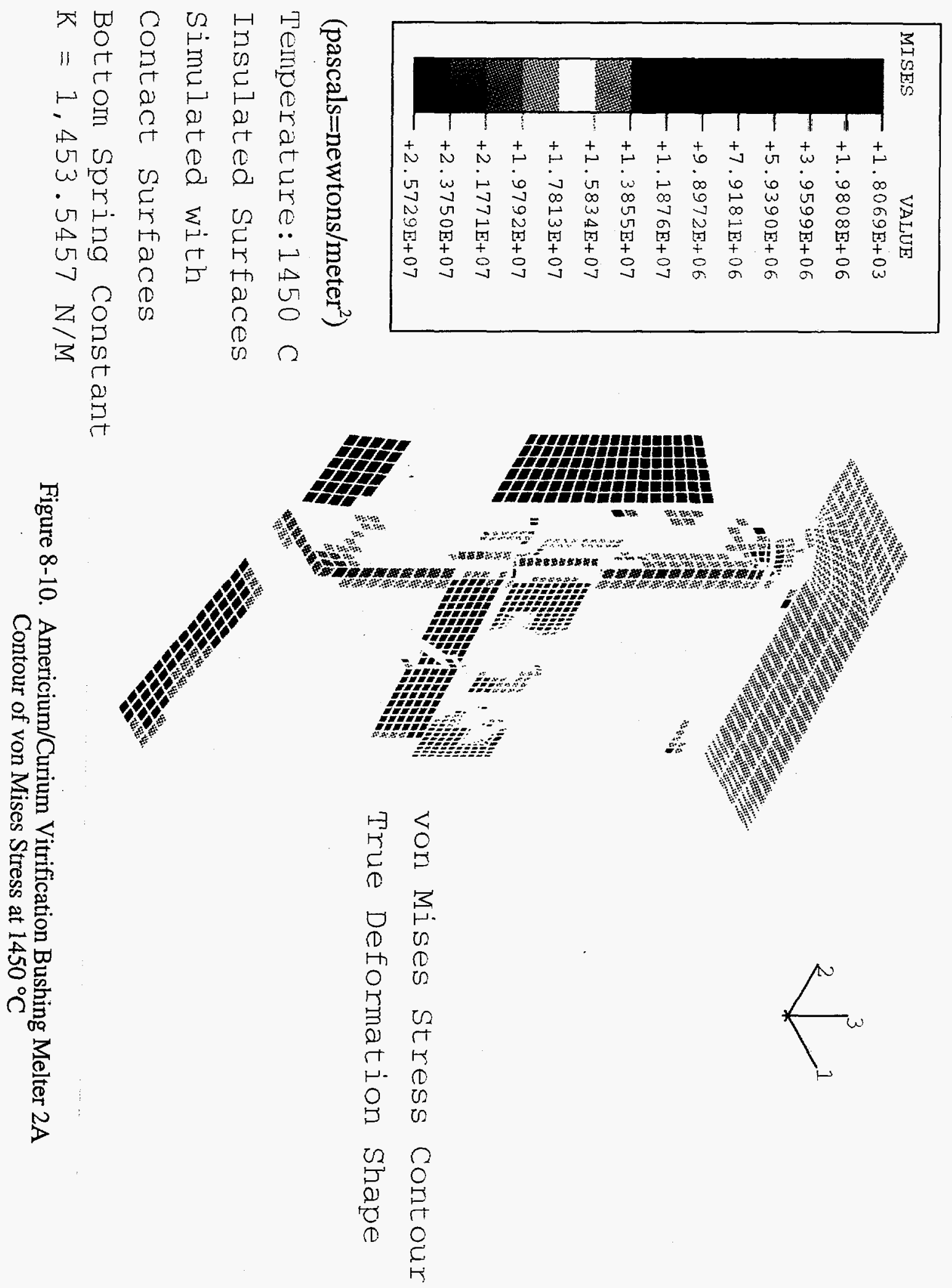